\title{
Use of evolutionary computing for modelling some complex problems
}

in geotechnical engineering

Mohamed A. Shahin

Department of Civil Engineering, Curtin University, Perth, Australia

GPO Box U1987, Perth WA 6845, Australia; Phone: +61-8-9266 1822; Fax: +61-89266 2681; E-mail”m.shahin@curtin.edu.au 


\section{Use of evolutionary computing for modelling some complex problems in geotechnical engineering}

In this paper, the feasibility of using evolutionary computing for solving some complex problems in geotechnical engineering is investigated. The paper presents a relatively new technique, i.e. evolutionary polynomial regression (EPR), for modelling three practical applications in geotechnical engineering including the settlement of shallow foundations on cohesionless soils, pullout capacity of small ground anchors and ultimate bearing capacity of pile foundations. The prediction results from the proposed EPR models are compared with those obtained from artificial neural network (ANN) models previously developed by the author, as well as some of the most commonly available methods. The results indicate that the proposed EPR models agree well with (or better than) the ANN models and significantly outperform the other existing methods. The advantage of EPR technique over ANNs is that EPR generates transparent and well-structured models in the form of simple and easy-to-use hand calculation formulae that can be readily used by practising engineers.

Keywords: geotechnical engineering; modelling; evolutionary polynomial regression; settlement; shallow foundations; pullout capacity; ground anchors; bearing capacity; pile foundations

\section{Introduction}

Geotechnical engineering deals with materials such as soil and rock that, by their very nature, exhibit varied and uncertain behaviour due to the imprecise physical processes associated with the formation of these materials. Modelling the behaviour of such materials in geotechnical engineering applications is complex and usually beyond the ability of most traditional forms of physically-based engineering methods. Artificial intelligence (AI) is becoming more popular and particularly amenable to modelling the complex behaviour of most geotechnical engineering materials as it has demonstrated superior predictive ability compared to traditional methods. Among the AI techniques that have been widely used in geotechnical engineering is the artificial neural networks (ANNs). Over the last decade, ANNs have been applied to a wide range of problems in geotechnical engineering, and interested readers are referred to Shahin et al. (2001), where the pre-2001 applications are reviewed in some detail, and Shahin et al. (2009), 
where the post-2001 applications are briefly examined.

The architecture and operation of ANNs have been covered by many authors (e.g. Fausett 1994; Zurada 1992). Typically, the architecture of ANNs consists of a series of processing elements (PEs), or nodes, that are usually arranged in layers: an input layer, an output layer and one or more hidden layers. The input from each PE in the previous layer is multiplied by an adjustable connection weight, and at each PE, the weighted input signals are summed and a threshold value is added. This combined input is then passed through a non-linear transfer function to produce the output of the PE, which provides the input to the PEs in the next layer. The propagation of information in an ANN starts at the input layer where the input data are presented. The network adjusts its weights on the presentation of a training data set and uses a learning rule to find a set of weights that produces the input/output mapping that has the smallest possible error. This process is called 'learning' or 'training'. Once this has been successfully accomplished, the performance of the trained model needs to be verified using an independent validation set.

Despite the success of ANNs in the analysis of many geotechnical engineering applications, they have some drawbacks such as the lack of transparency and knowledge extraction, leading this technique to be criticised as being black boxes (Ahangar-Asr et al. 2011). This is due to the complexity of the obtained network structure as the acquired knowledge is represented in the form of a set of weights and biases that are difficult to interpret. Due to their lack of ability to provide insights of how model inputs affect outputs, ANNs neither consider nor explicitly explain the underlying physical processes of the problem at hand. Consequently, ANNs usually fail to give a transparent function that relates the inputs to outputs, making it difficult to understand the nature of the input-output relationships that are derived (Shahin 2013). This urged researchers to find alternative $\mathrm{AI}$ techniques that can overcome most ANN drawbacks, one of these techniques is the evolutionary polynomial regression (EPR), which will be the main concern of this paper. EPR is a relatively new AI approach, based on evolutionary computing, that aims to search for simple and optimal structures to represent a system through a combination of the genetic algorithm and least-square method.

The main objective of the current paper is to explore the feasibility of utilising the EPR technique to develop simple and transparent prediction models for solving some complex problems in geotechnical engineering. In this paper, the capability of the EPR 
technique is demonstrated via three applications in geotechnical engineering including the settlement of shallow foundations on cohesionless soils, pullout capacity of small ground anchors and ultimate bearing capacity of pile foundations. The author has previously used ANNs for modelling the above applications and has demonstrated some success (see Shahin 2010; Shahin and Jaksa 2005; Shahin et al. 2002b). These applications are revisited herein in view of the evolutionary computing using EPR technique in an attempt to develop more reliable and well-structured models. The predictive ability of the proposed EPR models is examined by comparing their results with experimental data, and with those obtained from the ANN models previously developed by the author as well as some of the most commonly available methods. Sensitivity analyses are also carried out to explore the generalisation ability (robustness) of the developed EPR models in interpreting the underlying physical meaning compared with available geotechnical engineering knowledge, and to examine the significance of model inputs.

\section{Overview of evolutionary polynomial regression}

Evolutionary polynomial regression (EPR) is a hybrid regression technique that is based on the evolutionary computing developed by Giustolisi and Savic (2006). In recent years, EPR has been applied to some problems in civil engineering (e.g. Ahangar-Asr et al. 2011; Berardi et al. 2008; Savic et al. 2006) and has shown high potential. It constructs symbolic models by integrating the soundest features of numerical regression and genetic algorithms, as explained below. The following two steps roughly describe the underlying features of the EPR technique. In the first step, the selection of the best model structure in the form of polynomial expressions is carried out by employing an evolutionary searching strategy via means of genetic algorithms (Goldberg 1989). In the second step, numerical regression using the least square method is conducted, aiming to estimate the parameters of the previously selected polynomial expressions. The general form of expression in EPR can be presented as follows (Savic et al. 2006):

$$
y=\sum_{j=1}^{m} F\left(X, f(X), a_{j}\right)+a_{o}
$$

where: $y$ is the estimated vector of output of the process; $m$ is the number of terms of the target expression; $F$ is a function constructed by the process; $X$ is the matrix of input 
variables; $f$ is a function defined by the user; and $a_{j}$ is a constant. A typical example of EPR pseudo-polynomial model structure (expression) that belongs to the class of Eqn. (1) is expressed in the vector form, as follows (Giustolisi and Savic 2006):

$$
\hat{Y}=a_{o}+\sum_{j=1}^{m} a_{j} \cdot\left(X_{1}\right)^{E S(j, 1)} \ldots\left(X_{k}\right)^{E S(j, k)} \cdot f\left[\left(X_{1}\right)^{E S(j, k+1)} \ldots\left(X_{k}\right)^{E S(j, 2 k)}\right]
$$

where: $Y$ is the vector of target values; $X_{i}$ are the vectors of the $k$ candidate inputs; $E S$ is the matrix of exponents; $f$ is a function selected by the user; $a_{j}$ are the values of the constants; and $m$ is the length of the expression.

EPR is suitable for modelling physical phenomena, based on two features (Savic et al. 2006): (i) the introduction of prior knowledge about the physical system/process - to be modelled at three different times, namely before, during and after EPR modelling calibration; and (ii) the production of symbolic formulas, enabling data mining to discover patterns which describe the desired parameters. In the first EPR feature (i) above, before the construction of the EPR model, the modeller selects the relevant inputs and arranges them in a suitable format according to their physical meaning. During the EPR model construction, model structures are determined by following some user-defined settings such as general polynomial structure, user-defined function types (e.g. natural logarithms, exponentials, tangential hyperbolics) and searching strategy parameters. The EPR starts from true polynomials and also allows for the development of non-polynomial expressions containing user-defined functions (e.g. natural logarithms). The user physical insight and engineering judgement can be incorporated into the model to make hypotheses on the elements and structure of the selected objective functions, enabling the refinement of the final models (Giustolisi and Savic 2006). After EPR model calibration, an optimum model can be selected from among the series of returned models. The optimum model is selected based on the modeller's judgement, in addition to statistical performance indicators, e.g. the coefficient of determination. A typical flow diagram of the EPR procedure is shown in Figure 1 (Rezania et al. 2011), and detailed description of the technique can be found in Giustolisi and Savic (2006).

The fact that EPR is similar to ANNs in the sense that both techniques are based on observed data (i.e. data driven approaches); however, unlike ANNs, EPR can return a 
simple mathematical structure that is symbolic and usually uncomplicated (Giustolisi et al. 2007). The nature of the obtained EPR models permits global exploration of expressions, which provides insights into the relationship between the model inputs and corresponding outputs, i.e. allows the user to gain additional knowledge of how the system performs. An additional advantage of EPR over ANNs is that the structure and network parameters of ANNs (e.g. number of hidden layers and their number of nodes, transfer functions, learning rate, etc.) should be identified a priori and are usually obtained using ad-hoc, trial-and-error approaches. However, the number and combination of terms, as well as the values of EPR modelling parameters, are all evolved automatically during model calibration. At the same time, the prior physical knowledge based on engineering judgment or human expert can be incorporated to make hypotheses on the elements of the objective functions and their structure, enabling refinement of the final models.

\section{Development of EPR models}

As previously mentioned, three geotechnical engineering applications are selected to illustrate the modelling capability of the EPR approach. In this work, the EPR models were developed using the computer-based software package EPR TOOLBOX Version 2.0 (Laucelli et al. 2009). For each particular application, the following steps were followed. The data used to calibrate and validate the EPR models were obtained from the literature and comprise several in-situ case records. The available data were divided into two sets: a training set (the extreme values of the data were included in this set) for model calibration and an independent validation set for model verification. As recommended by Masters (1993) and Shahin et al. (2004), the data were divided into their sets in such a way that they are statistically consistent and thus represent the same statistical population. The statistics used include the mean, standard deviation, minimum, maximum and range. In total, $80 \%$ of the available data were used for model training and $20 \%$ for validation, as this is the most commonly used data division found in the literature. Detailed information about data division can be found in Shahin et al. (2004). For brevity and due to the limited space, full details of the data used in each application are not given herein but their ranges will be presented later. In the meantime, the database used for each model is made available for interested readers 
upon request. This also includes EPR model predictions and the ratio of measured to predicted output values.

Following the data division, the input and output variables were presented to the EPR for model training and a set of internal model parameters was tried in an attempt to arrive at an optimal model, by selecting the related internal parameters for evolving the model. The optimisation phase was undertaken as follows. Before presenting the data to the EPR for training, the input and output variables were pre-processed by scaling them between 0.0 and 1.0 so as to eliminate their dimension and ensure that all variables receive equal attention during training. The polynomial structure of the EPR was assumed in such a way that each regression term was consisted of elements from $X$ that were raised to pre-specified power values. The assumed range of possible exponents of terms from $X$ was $(-2 ;-1 ;-0.5 ; 0 ; 0.5 ; 1 ; 2)$. As explained by Giustolisi et al. (2007), the exponent 0 is useful for deselecting the non-necessary inputs, the exponents $(-0.5$ and 0.5) smooth the effect of the inputs, the exponents (-1 and 1) produce a linear effect of the inputs and the exponents (-2 and 2) amplify the inputs. The maximum length of the polynomial structure was assumed to be 5 terms and the bias term was assumed to be zero. Finally, the least square search was performed for positive coefficients only, i.e. $a_{j}$ $>0$, and was obtained using the Singular Value Decomposition based solver (Giustolisi and Savic 2006).

Once the training phase of the models has been successfully accomplished, the performance of the trained models was verified using the validation set. The purpose of model validation phase is to examine the predictive ability of the model in cases that have not been used as part of the model training process. If such performance is adequate, the model is deemed to be robust. The strategy used for assessing the best model out of several generated models is that a model is deemed to be optimal if it combines three categories: (i) it provides good performance in the validation set; (ii) it has consistent performance in the validation set with that obtained in the training set; and (iii) it has simple structure with minimum number of model parameters.

The performance of the proposed EPR models in the training and validation sets was evaluated using five analytical standard measures including the coefficient of correlation, $r$, the coefficient of determination, $R^{2}$, root mean squared error, RMSE, mean absolute error, $M A E$, and ratio of average measured to predicted outputs, $\mu$. The formulas that govern these measures are expressed as follows: 


$$
\begin{gathered}
r=\frac{\sum_{i=1}^{N}\left(O_{i}-\bar{O}\right)\left(P_{i}-\bar{P}\right)}{\sqrt{\sum_{i=1}^{N}\left(O_{i}-\bar{O}\right)^{2} \sum_{i=1}^{N}\left(P_{i}-\bar{P}\right)^{2}}} \\
R^{2}=1-\frac{\sum_{i=1}^{N}\left(O_{i}-P_{i}\right)^{2}}{\sum_{i=1}^{N}\left(O_{i}-\bar{O}\right)^{2}} \\
R M S E=\sqrt{\frac{\sum_{i=1}^{N}\left(O_{i}-P_{i}\right)^{2}}{N}} \\
M A E=\frac{1}{N} \sum_{i=1}^{N}\left|O_{i}-P_{i}\right| \\
\mu=\frac{\bar{O}}{\bar{P}}
\end{gathered}
$$

where: $N$ is the number of data points presented to the model; $O_{i}$ and $P_{i}$ are the observed and predicted outputs, respectively; and $\bar{O}$ and $\bar{P}$ are the arithmetic average of the observed and predicted outputs, respectively.

The coefficient of correlation, $r$, is a measure that is used to determine the relative correlation between the predicted and observed outputs. However, as indicated by Das and Sivakugan (2010), $r$ sometimes may not necessarily indicate better model performance due to the tendency of the model to deviate toward higher or lower values, particularly when the data range is very wide and most of the data are distributed about their mean. Consequently, the coefficient of determination, $R^{2}$, was used as it can give an unbiased estimate and may be a better measure for model performance. The RMSE is the most popular error measure and has the advantage that large errors receive much greater attention than small errors (Hecht-Nielsen 1990). However, as indicated by Cherkassky et al. (2006), there are situations when RMSE cannot guarantee that the model performance is optimal, thus, MAE was also used. The MAE eliminates the emphasis given to large errors, and is desirable when the data evaluated are smooth or continuous. The measure, $\mu$, was obtained by calculating the arithmetic mean of the ratio of the measured to predicted outputs, and the optimal performance of a model is obtained based on this measure when $\mu$ approaches unity. 
In order to examine the prediction accuracy of the EPR models compared to currently available methods, their predictions in the validation set were compared with those obtained from the ANN models previously developed by the author, as well as some of the most commonly available methods. It should be emphasized that the comparison of EPR models with other methods was based on the validation only rather than the training set, as this is the set that has not been used as part of the EPR model building process. This is important so as to provide a fair and genuine comparison.

Sensitivity analyses were also carried out as an additional validation tool to explore the generalisation ability (robustness) of EPR models in interpreting the underlying physical meaning of the problems considered, and to examine the significance of model inputs. In order to do so, all input variables in each model, except one, were fixed to the mean values used in model training and a set of synthetic data (whose values lie between the minimum and maximum values used in model training), were generated for the single input that was allowed to vary. The synthetic data were generated by increasing their values by a certain percentage of the total range between the minimum and maximum values. These input values were then entered into EPR models and the corresponding outputs were obtained. This process is repeated for the next input variable and so on, until the models response has been examined for all inputs. The robustness of the models was then determined by examining how well the predicted outputs agree with the known underlying physical meaning based on available geotechnical engineering knowledge.

\subsection{Application A: Settlement of shallow foundations on cohesionless soils}

Settlement prediction is an essential criterion in the design of shallow foundations on cohesionless soils and usually controls the design process, rather than bearing capacity, especially when the breadth of footing exceeds $1 \mathrm{~m}$ (Schmertmann 1970). In this application, a database that contains 187 data records of field measurements of settlement of shallow foundations as well as the corresponding information regarding the footings and soil were used for the EPR model development. The data were obtained from the literature and cover a wide range of variation in footing dimensions and cohesionless soil types and properties. Details of the references from which the data were obtained can be found in Shahin et al. (2002a). The model inputs include, as the main factors affecting settlement, footing width, $B$, footing net applied pressure, $q$, average SPT blow count $/ 300 \mathrm{~mm}, N$, over the depth of influence of the foundation, 
footing length, $L$, and footing embedment depth, $D_{f}$. Settlement, $S$, is the single output variable. The statistics of the data used for this application are given in Table 1 including the mean, standard deviation and range.

It should be noted that there is no unanimous agreement in the literature for the definition of the depth of influence of a foundation. In this work, the following guidelines, proposed by Burland and Burbidge (1985), were used, as follows. When $N$ is decreasing with depth, it was taken to be equal to the lesser of $2 B$ or the depth from the bottom of the footing to bedrock. On the other hand, when $N$ is constant or increasing with depth, the depth of influence was taken to be equal to $B^{0.75}$. It should be also noted that Burland and Burbidge (1985) recommended no correction to $N$ be taken for overburden pressure or submergence. However, for very fine and silty sand below the water table, they suggested the submergence correction proposed by Terzaghi and Peck (1948) when $N>15$, as follows:

$$
N_{\text {corrected }}=15+0.5(N-15)
$$

Also, for gravel or sandy gravel, Burland and Burbidge (1985) proposed a correction for $N$, as follows:

$$
N_{\text {corrected }}=1.25 \mathrm{~N}
$$

Since most case records in the database used in the current study were obtained from Burland and and Burbidge (1985), these corrections were also considered and applied to the entire database. The EPR returned several different models and the one selected to be optimal is as follows:

$$
S=-8.327 \frac{q}{N^{2} L}+8.849 \frac{q}{N^{2}}+2.993 \frac{B \sqrt{q}}{N}-0.651 \frac{B \sqrt{q D_{f}}}{N}+2.883
$$

The performance of the developed EPR model in the training and validation sets are given in Table 2 and its comparison with the other available methods in the validation set is illustrated in Table 3. The methods considered for comparison include the ANN model developed by Shahin et al. (2002b), Meyerhof (1965) method, Schultze and 
Sherif (1973) method and Schmertmann et al. (1978) method. The performance measures of the EPR model in Table 2 indicates that the model performs well in both the training and validation sets, and that the EPR model performance during training is generally consistent with that obtained during validation, indicating good predictive ability of the EPR model. The comparison results in Table 3 for the validation set demonstrate that the EPR model outperforms all other methods, including the ANNs, in all the performance measures used.

The performance of the EPR model for this application in the training and validation sets is further investigated graphically, as shown in Figure 2, whereas the results of the sensitivity analysis are shown in Figure 3. In Figure 2, obviously good performance is obtained when the model provides minimal scattering around the 1:1 line, while better means of visual judgement can be made through the two other dashed lines that indicate $\pm 10 \%$ deviation from the perfect agreement. It can be seen that despite some discrepancy in a few points, the EPR model exhibits good overall performance in both the training and validation sets. The sensitivity analysis in Figure 3 shows that predicted settlements of shallow foundations from EPR model agree well with what one would expect based on the underlying physical meaning of the geotechnical engineering knowledge. For example, the settlement increases with the increase of the footing width, applied pressure and footing length. On the other hand, the settlement decreases with the increase of the SPT blow count and footing embedment depth. It can also be seen that, within the ranges of the synthetic data used, the footing width, applied pressure and SPT blow count seem to be the most significant factors affecting settlement compared to the footing length and embedment depth. Moreover, the footing embedment depth tends to have a moderate impact on settlement, while the footing length has the smallest impact on settlement. These results agree well with those obtained from a sensitivity analysis carried on the ANN model previously developed by the author (see Shahin et al. 2002b), by examining the connection weights of the trained neural network using Garson method (Garson 1991).

\section{Illustrative numerical example}

A rectangular footing whose dimensions are $2.5 \times 4.0 \mathrm{~m}$ is founded at a depth equal to $1.5 \mathrm{~m}$ below the ground surface. The soil beneath the footing is sand that extends to a depth in excess of two times its width. The net applied load pressure on the footing is 
$350 \mathrm{kPa}$ and the average SPT blow count over a depth of two times its width is 16 . The settlement is required.

\section{Solution}

Given the information provided, then $B=2.5 \mathrm{~m} ; q=350 \mathrm{kPa} ; N=16 ; L=4.0 \mathrm{~m}$; and $D_{f}$ $=1.5 \mathrm{~m}$. From Equation (10):

$$
\begin{aligned}
& S=\left(-8.327 \times \frac{350}{16^{2} \times 4}\right)+\left(8.849 \times \frac{350}{16^{2}}\right)+\left(2.993 \times \frac{2.5 \times \sqrt{350}}{16}\right) \\
& -\left(0.651 \times \frac{2.5 \times \sqrt{350 \times 1.5}}{16}\right)+2.883=18.6 \mathrm{~mm}
\end{aligned}
$$

\subsection{Application B: Pullout capacity of small ground anchors}

Small ground anchors are those used to resist uplift forces imposed predominantly by wind acting on the temporary light structures, such as marquees, which are mainly connected to the ground by these anchors. The anchors are often installed vertically, to transmit the tensile forces from the structure to the surrounding soil. The shear strength of the surrounding soil resists these tensile forces, hence, provides structural stability. Traditionally, these anchors are made of steel rods, less than one metre in length, and have different diameters and shapes and are driven into the ground, usually by means of a sledge hammer. The pullout capacity of these ground anchors is affected by many factors including the length of anchor embedment; anchor diameter; anchor surface roughness; properties of the soil surrounding the anchor; and installation technique used for anchor placement. There are almost no models available, other than very rudimentary, for the pullout capacity of small ground anchors and currently used methods are those applied almost exclusively to the axial capacity of single piles. Since such small ground anchors are, in effect micro-piles, it is reasonable to expect that the available single pile models should apply equally to these anchors; as the physics is identical, only the scale is different. However, these pile methods have been found to be inaccurate and incomplete when used for small ground anchors (Lau and Simmons 1986). This can be attributed to the fact that the mechanics and behaviour of small ground anchor is not well understood (Su and Fragaszy 1988), and available models for predicting the pullout capacity of such ground anchors have been originally developed to estimate the axial capacity of single piles in compression rather than tension. In this 
paper, the use of EPR is investigated for modelling the pullout capacity of small ground anchors.

The database used for developing the EPR model contains 119 in-situ pullout tests that were conducted on rough mild steel anchors, given by Shahin and Jaksa (2006). The tests were carried out on sites of different soil types (cohesive and cohesionless soils) and geotechnical conditions. The anchors used have different shapes (i.e. circular, hexagonal and star dropper) and were embedded vertically on the ground at various embedment lengths (i.e. 400, 600 and $800 \mathrm{~mm}$ ). The anchors were either installed into the ground statically by means of a steady penetration provided by a hydraulic ram associated with a drilling rig or dynamically using a sledge hammer. The statistics of the data used are given in Table 4.

Five input variables were used in the EPR model including the anchor equivalent diameter, $D$ (= anchor perimeter/ $\pi$ ); anchor embedment length, $L$; arithmetic average cone tip resistance, $\bar{q}_{c}$, along the embedment length; arithmetic average sleeve friction, $\bar{f}_{s}$, along the embedment length; and the installation technique, which was assigned a numeric value of 1 for static installation and 2 for dynamic installation (this is due to the fact that AI techniques deal only with numeric values rather than text). The single model output is the ultimate pullout capacity, $Q_{u}$. The EPR returned an optimal model that gives the following two formulas, for static and dynamic installation, respectively:

$$
\begin{aligned}
& Q_{u}=-0.376 \sqrt{\bar{q}_{c}}-6.727 \times 10^{-9} L \bar{q}_{c}^{2} \bar{f}_{s}^{2}+5.357 \times 10^{-5} L \sqrt{D \bar{q}_{c} \bar{f}_{s}}+0.75 \\
& Q_{u}=-0.376 \sqrt{2 \bar{q}_{c}}-6.727 \times 10^{-9} L \bar{q}_{c}^{2} \bar{f}_{s}^{2}+5.357 \times 10^{-5} L \sqrt{D \bar{q}_{c} \bar{f}_{s}}+0.75
\end{aligned}
$$

The performance of the EPR model in the training and validation sets is given in Table 5, and the comparison of model performance in the validation set with the other available methods in given in Table 6. The methods used for comparison include the ANN model developed by Shahin and Jaksa (2005), LCPC method (Bustamante and Gianeselli 1982), Das (1995) method and Bowles (1997) method. It can be seen in Table 5 that the EPR model performs well in the training and validation sets, and that the model performance is consistent in both the training and validation sets. It can also 
been seen in Table 6 that the EPR model outperforms the other available methods including the ANN model.

The performance of EPR model for this application in the training and validation sets is shown graphically in Figure 4, which indicates good overall model performance in both the training and validation sets. The results of the sensitivity analysis are shown in Figure 5, which indicates that the behaviour of EPR model is in good agreement with the underlying physical meaning of this application. For example, it can be seen that there is an increase in the pullout capacity with the increase of the anchor diameter, embedment length, cone tip resistance and cone sleeve friction, as expected. It is also interesting to observe that static installation produces higher pullout capacity than dynamic installation. This is because static installation causes less lateral disturbance to the adjacent soil than dynamic installation, providing increased shaft adhesion and hence greater pullout capacity. The above results agree well with the results of a sensitivity analysis carried out by the author on a previously developed ANN model (see Shahin and Jaksa 2005).

\section{Illustrative numerical example}

A circular cross-section anchor with a diameter of $25 \mathrm{~mm}$ is embedded into the ground to a depth of $600 \mathrm{~mm}$ using: (a) a static push; and (b) a sledge hammer. The soil along the anchor embedment depth has an average cone tip resistance of $2 \mathrm{MPa}$ and an average sleeve friction of $120 \mathrm{kPa}$. The ultimate pullout capacity is required.

\section{Solution:}

Given the information provided, $D=25 \mathrm{~mm} ; L=600 \mathrm{~mm} ; \bar{q}_{c}=2 \mathrm{MPa}$; and $\bar{f}_{s}=$ $120 \mathrm{kPa}$.

(a) For static installation, Equation (11) is applied and the predicted pullout capacity can be obtained as follows:

$Q_{u}=(-0.376 \sqrt{2})-\left(6.727 \times 10^{-9} \times 600 \times 2^{2} \times 120^{2}\right)$

$+\left(5.357 \times 10^{-5} \times 600 \times \sqrt{25 \times 2 \times 120}\right)+0.75=2.48 \mathrm{kN}$

(b) For dynamic installation (sledge hammer), Equation (12) is applied and the predicted pullout capacity can be obtained as follows:

$Q_{u}=(-0.376 \times \sqrt{2 \times 2})-\left(6.727 \times 10^{-9} \times 600 \times 2^{2} \times 120^{2}\right)$

$+\left(5.357 \times 10^{-5} \times 600 \times \sqrt{25 \times 2 \times 120}\right)+0.75=2.26 \mathrm{kN}$ 
Hence, in this example, dynamically installation results in almost $9 \%$ lower pullout capacity when compared with static installation.

\subsection{Application C: Bearing capacity of pile foundations}

Numerous methods are currently available for predicting the axial capacity of pile foundations (driven piles and drilled shafts). However, among available methods, the cone penetration test (CPT) based models have been shown to give better predictions in many situations. This can be attributed to the fact that CPT results yield more reliable soil properties, leading to more accurate axial pile capacity predictions. In this paper, two EPR models (one for driven piles and the other for drilled shafts) were developed. The data used to calibrate and validate the EPR models include a series of 79 in-situ driven pile load tests and 94 in-situ drilled shaft load tests, as well as CPT results. The conducted tests were located on sites of different soil types and geotechnical conditions, ranging from cohesive clays to cohesionless sands. The driven pile load tests include compression and tension loading conducted on steel and concrete piles. The driven piles used have different shapes (i.e. circular, square and hexagonal) and range in diameter between $250 \mathrm{~mm}$ to $900 \mathrm{~mm}$ and embedment lengths between $5.5 \mathrm{~m}$ to $41.8 \mathrm{~m}$. The drilled shaft load tests were conducted on straight and belled concrete piles and include compression and tension loading but no tension loading for belled shafts. The drilled shafts used have stem diameters ranging from $305 \mathrm{~mm}$ to $1798 \mathrm{~mm}$ and embedment lengths from $4.5 \mathrm{~m}$ to $27.4 \mathrm{~m}$. The statistics of the data used are given in Table 7. Details of the inputs and outputs used in both the driven piles and drilled shafts are described below.

\subsubsection{Driven piles}

Seven factors affecting the capacity of driven piles were presented to the EPR as potential model input variables. These include the pile equivalent diameter, $D=$ pile perimeter $/ \pi$; pile embedment length, $L$; weighted average cone point resistance over pile tip failure zone, $\bar{q}_{c-t i p}$; weighted average cone sleeve friction over pile tip failure zone, $\bar{f}_{s-t i p}$; weighted average cone point resistance over pile embedment length, $\bar{q}_{c-s h a f t}$; weighted average cone sleeve friction over pile embedment length, $\bar{f}_{s-s h a h f t}$; and pile material, which is translated from the text format (i.e. steel or concrete) into arbitrary numeric values (i.e. 1 for steel and 2 for concrete). The ultimate pile capacity, $Q_{u}$, is the 
single model output variable. It should be noted that the following conditions were applied to the input and output variables used in the EPR driven piles model:

- The weighted averages over which $q_{c}$ and $f_{s}$ were calculated have been obtained using the following formula:

$$
\bar{x}=\frac{\sum_{i=1}^{i=n}\left[\left|x_{i+1}-x_{i}\right| \times\left(h_{i+1}-h_{i}\right)\right]}{\sum_{i=1}^{i=n}\left(h_{i+1}-h_{i}\right)}
$$

where: $x_{i}, x_{i+1}, \ldots, x_{n}$ are the values of the CPT reading (e.g. $q_{c}$ and $\left.f_{s}\right)$ at depths from the ground surface equal to $h_{i}, h_{i+1}, \ldots, h_{n}$.

- The ultimate pile capacity, $Q_{u}$, was taken to be at the plunging failure for the welldefined failure cases, and at $80 \%$-criterion for the cases that failure load is not clearly defined, as suggested by Eslami (1996). The 80-criterion defines the ultimate load as the load that gives four times the movement of the pile head as obtained for 80 percent of that load, and more details can be found in Brinch-Hansen (1963).

- The pile tip failure zone over which $\bar{q}_{c-t i p}$ and $\bar{f}_{s-t i p}$ are calculated was taken in accordance with Eslami (1996), in which the influence zone extends to $4 D$ below and $8 D$ above pile toe when the pile toe is located in non-homogeneous soil of dense strata with a weak layer above. Also, in non-homogeneous soil, when the pile toe is located in weak strata with a dense layer above, the influence zone extends to $4 D$ below and $2 D$ above pile toe. In homogeneous soil, however, the influence zone extends to $4 D$ below and above the pile toe.

- Both values of the cone point resistance and sleeve friction of the CPT tests were incorporated as model inputs, allowing the soil type (classification) to be considered in the EPR model.

- Several CPT tests used in this work include mechanical rather than electric CPT data and thus, it was necessary to convert the mechanical CPT readings into equivalent electric CPT values as the electric CPT is the one that is commonly used nowadays. This was carried out for the cone point resistance using the following correlation proposed by Kulhawy and Mayne (1990): 


$$
\left(\frac{q_{c}}{p_{a}}\right)_{\text {Electric }}=0.47\left(\frac{q_{c}}{p_{a}}\right)_{\text {Mechanical }}^{1.19}
$$

where: $p_{a}$ is the atmospheric pressure and $q_{c}$ is the cone point resistance. For the cone sleeve friction, the mechanical cone gives higher readings than the electric cone in all soils with a ratio in sands of about 2, and 2.5-3.5 for clays (Kulhawy and Mayne 1990). In the current work, a ratio of 2 was used for sands and 3 for clays.

\subsubsection{Drilled shafts}

The input variables that are considered to be significant in prediction of the ultimate capacity of drilled shafts include the pile stem diameter, $D$; pile base diameter, $B$; pile embedment length, $L$; weighted average cone point resistance over pile failure zone, $\bar{q}_{c-t i p}$; weighted average sleeve friction over pile failure zone, $\bar{f}_{s-t i p}$; weighted average cone point resistance over pile embedment length, $\bar{q}_{c-s h a f t}$; and weighted average sleeve friction over pile embedment length, $\bar{f}_{s-s h a h f t}$. These parameters were presented to the EPR model as potential model input variables, and the ultimate drilled shaft capacity, $Q_{u}$, is the single model output variable. It should be noted that the following conditions were applied to the input and output variables used in the EPR drilled shafts model:

- The ultimate bearing capacity, $Q_{u}$, for drilled shafts under compression was taken as the axial load measured at a displacement equal to $5 \%$ of pile base diameter plus the elastic compression of the pile (i.e. $P L / E A$, where $P$ is the applied load, $L$ is the pile length, $A$ is the pile cross-sectional area and $E$ is the pile elastic modulus). On the other hand, $Q_{u}$ for drilled shafts under tension was defined as the axial load at $12 \mathrm{~mm}$ (0.5 inch) of displacement. The above criteria for determination of ultimate load are as suggested by Alsamman (1995) and recommended by Reese and O’Neill (1988).

- The pile base failure zone over which $\bar{q}_{c-t i p}$ and $\bar{f}_{s-t i p}$ are calculated was taken in accordance with Alsamman (1995) to be equal to one diameter depth beneath the pile base.

- As with the driven piles, both values of the cone point resistance and sleeve friction of the CPT tests were incorporated as model inputs, allowing the soil type (classification) to be considered in the EPR model. 
- The majority of records for cone point resistance are mechanical and thus, were converted to the equivalent electric values using Eqn. (14).

\subsubsection{Formulations and performance of EPR models}

The EPR returned models that are represented by the following formulas.

For driven (steel) piles:

$$
\begin{gathered}
Q_{u(\text { steel-driven })}=-2.277 \frac{D \bar{q}_{c-t i p}}{\sqrt{\bar{q}_{c-\text { shaft }} \bar{f}_{s-\text { shaft }}}}+0.096 D L+1.714 \times 10^{-4} D^{2} \bar{q}_{c-t i p} \sqrt{L} \\
-6.279 \times 10^{-9} D^{2} L^{2} \sqrt{\bar{q}_{c-t i p} \bar{f}_{s-t i p}}+243.39
\end{gathered}
$$

Alternatively, for driven (concrete) piles:

$$
\begin{gathered}
Q_{u(\text { concrete-driven })}=-2.277 \frac{D \bar{q}_{c-t i p}}{\sqrt{\bar{q}_{c-\text { shaft }} \bar{f}_{s-\text { shaft }}}}+0.096 D L+1.714 \times 10^{-4} D^{2} \bar{q}_{c-t i p} \sqrt{L} \\
-6.279 \times 10^{-9} D^{2} L^{2} \sqrt{\bar{q}_{c-t i p} \bar{f}_{s-t i p}}+486.78
\end{gathered}
$$

For drilled shafts:

$$
\begin{gathered}
Q_{u(\text { drilled-shafts })=0.6878 L^{2} \sqrt{\bar{f}_{s-s h a f t}}}+1.581 \times 10^{-4} B^{2} \sqrt{\bar{f}_{s-s h a f t}}+1.294 \times 10^{-4} L^{2} \bar{q}_{c-t i p}^{2} \sqrt{D} \\
+7.8 \times 10^{-5} D \bar{q}_{c-s h a f t} \bar{f}_{s-s h a f t} \sqrt{\bar{f}_{s-t i p}}
\end{gathered}
$$

The performance of the EPR models in the training and validation sets is given in Table 8 , and the performance comparison of the models in the validation set with the 
other available methods is given in Table 9. For driven piles, the methods considered for comparison include the ANN model developed by Shahin (2010), European method (de Ruiter and Beringen 1979), LCPC method (Bustamante and Gianeselli 1982) and Eslami and Fellenious (1997) method. For drilled shafts, the methods considered include the ANN model (Shahin 2010), Schmertmann (1978) method, LCPC method (Bustamante and Gianeselli 1982) and Alsamman (1995) method. It can be seen in Table 8 that the performance of the EPR models in the training and testing sets, for both driven piles and drilled shafts, is good and consistent. It can also been seen in Table 9 that the performance of the EPR models is as good as the ANN model, or better, and outperforms the other available methods with the possible exception of Alsamman (1995).

The performance of EPR driven piles model is shown graphically in Figure 6, which indicates good overall performance in both the training and validation sets. The results of the sensitivity analysis are shown in Figure 7 , which indicates that the behaviour of EPR model agrees well with the underlying physical meaning of pile foundations. For example, it can be seen that there is an increase in the pile capacity with the increase of the pile diameter, embedment length, cone tip resistance and cone sleeve friction, as expected. However, the cone sleeve friction at the pile tip exhibits negligible impact on pile capacity. It can also be seen that concrete piles seem to exhibit higher pile capacity than steel piles, which is in agreement with what one would expect as concrete piles provide greater shaft adhesion than steel piles; hence, producing higher pile capacity.

Figure 8 shows the graphical performance of EPR drilled shafts model, whereas the model sensitivity analysis is shown in Figure 9. Again, Figure 8 demonstrates an overall good performance in the training and validation sets. On the other hand, Figure 9 shows that EPR model predictions agree well with one would expect based on the underlying physical meaning of behaviour of drilled shafts. For example, as expected, the shaft capacity increases with the increase of the pile stem diameter, pile base diameter, pile embedment length, cone tip resistance and cone sleeve friction. The above results agree well with the results of a sensitivity analysis carried out by the author on a previously developed ANN models (see Shahin 2010). 


\section{Illustrative numerical example}

A driven pile with a diameter of $300 \mathrm{~mm}$ is embedded into the ground to a depth of 15 $\mathrm{m}$. The soil has a weighted average cone point resistance of $5 \mathrm{MPa}$ over the pile tip failure zone and $6 \mathrm{MPa}$ along the pile length. The weighted average sleeve friction along the pile tip and length is 100 and $50 \mathrm{kPa}$, respectively. The ultimate pile capacity is required for both steel and concrete piles.

\section{Solution:}

Given the information provided, $D=300 \mathrm{~mm} ; L=15 \mathrm{~m} ; \bar{q}_{c-t i p}=5 \mathrm{MPa} ; \bar{f}_{s-t i p}=100$ $\mathrm{kPa} ; \bar{q}_{c-\text { shaft }}=6 \mathrm{MPa} ;$ and $\bar{f}_{s-\text { shahft }}=50 \mathrm{kPa}$.

(a) For steel piles, Equation (15) is applied as follows:

$$
\begin{aligned}
& Q_{u}=\left(-2.277 \times \frac{300 \times 5}{\sqrt{6 \times 50}}\right)+(0.096 \times 300 \times 15)+\left(1.714 \times 10^{-4} \times 300^{2} \times 5 \times \sqrt{15}\right) \\
& -\left(6.279 \times 10^{-9} \times 300^{2} \times 15^{2} \times \sqrt{5 \times 100}\right)+243.39=774.3 \mathrm{kN}
\end{aligned}
$$

(b) For concrete piles, Equation (16) is applied as follows:

$$
\begin{aligned}
& Q_{u}=\left(-2.277 \times \frac{300 \times 5}{\sqrt{6 \times 50}}\right)+(0.096 \times 300 \times 15)+\left(1.714 \times 10^{-4} \times 300^{2} \times 5 \times \sqrt{15}\right) \\
& -\left(6.279 \times 10^{-9} \times 300^{2} \times 15^{2} \times \sqrt{5 \times 100}\right)+486.78=1017.6 \mathrm{kN}
\end{aligned}
$$

Hence, in this example, the steel driven pile results in $24 \%$ lower ultimate pile capacity than the concrete pile. Equation (17) can be similarly used for predicting axial capacity of drilled shafts.

\section{Summary and conclusions}

The applicability of a new evolutionary computing technique, i.e. evolutionary polynomial regression (EPR), was investigated and assessed for modelling three applications in geotechnical engineering including the settlement of shallow foundations on cohesionless soils, pullout capacity of small ground anchors and bearing capacity of pile foundations including driven piles and drilled shafts. The predictive ability of the developed EPR models was examined by comparing their predictions with those obtained from in-situ experiments, and with those computed using previously developed artificial neural network (ANN) models as well as some of the most commonly available methods. Sensitivity analyses were carried out on the EPR models to examine their generalisation ability (robustness), and to explore the significance of model inputs. 
The advantage of EPR models over the ANN models is that EPR has the ability to present an explicit relationship between the model inputs and corresponding outputs. Consequently, the EPR models can be developed in the form of simple, transparent and well-structured equations that can be easily interpreted and can be readily used by practising engineers for hand calculations.

The results indicate that the EPR technique was capable of accurately modelling the three complex problems of geotechnical engineering considered in this study. The results also demonstrate that over the full range of the data used for model validation, the coefficient of correlation, $r$, coefficient determination, $R^{2}$, root mean squared error, $R M S E$, mean absolute error, $M A E$, and prediction ratio, $\mu$, obtained from the EPR models are found to be as good as those obtained from the previously developed ANN models, or better, and significantly outperform the other available methods (see Tables 3, 7 and 9) with the possible exception of Alsamman (1995). The sensitivity analyses also confirm that predictions from EPR models agree well with the underlying physical meaning based on the geotechnical engineering knowledge and what one would expect, leading to the conclusion that the developed EPR models can be used with confidence.

\section{References}

Ahangar-Asr, A., Faramarzi, A., Mottaghifard, N., and Javadi, A. A. (2011). "Modeling of permeability and compaction characteristics of soils using evolutionary polynomial regression." Computers and Geosciences, 37, 1860-1869.

Alsamman, O. M. (1995). "The use of CPT for calculating axial capacity of drilled shafts," PhD Thesis, University of Illinois-Champaign, Urbana, Illinois.

Berardi, L., Giustolisi, O., Kapelan, Z., and Savic, D. A. (2008). "Development of pipe deterioration models for water distribution systems using EPR." Journal of Hydroinformatics, 10(2), 113-126.

Bowles, J. E. (1997). Foundation analysis and design, McGraw-Hill, New York.

Brinch-Hansen, J. (1963). "Discussion on hyperbolic stress-strain response, cohesive soils." Journal of Soil Mechanics and Foundation Engineering, 89(SM4), 241242.

Burland, J. B., and Burbidge, M. C. (1985) "Settlement of foundations on sand and gravel." Proceedings of the Institution of Civil Engineers, London, 1325-1381.

Bustamante, M., and Gianeselli, L. (1982) "Pile bearing capacity prediction by means of static penetrometer CPT." Proceedings of the 2nd European Symposium on Penetration Testing, Amsterdam, 493-500.

Cherkassky, V., Krasnopolsky, V., Solomatine, D. P., and Valdes, J. (2006). "Computational intelligence in earth sciences and environmental applications: issues and challenges." Neural Networks, 19(2), 113-121.

Das, B. M. (1995). Principles of foundation engineering, 3rd Edition, PWS Publishing Company, Boston, MA. 
Das, S. K., and Sivakugan, N. (2010). "Discussion of: intelligent computing for modeling axial capacity of pile foundations." Canadian Geotechnical Journal, 47, 928-930.

de Ruiter, J., and Beringen, F. L. (1979). "Pile foundation for large North Sea structures." Marine Geotechnology, 3(3), 267-314.

Eslami, A. (1996). "Bearing capacity of piles from cone penetration test data," $\mathrm{PhD}$ Thesis, University of Ottawa, Ottawa, Ontario.

Eslami, A., and Fellenius, B. H. (1997). "Pile capacity by direct CPT and CPTu methods applied to 102 case histories." Canadian Geotechnical Journal, 34(6), 886-904.

Fausett, L. V. (1994). Fundamentals neural networks: Architecture, algorithms, and applications, Prentice-Hall, Englewood Cliffs, New Jersey.

Garson, G. D. (1991). "Interpreting neural-network connection weights." AI Expert, 6(7), 47-51.

Giustolisi, O., Doglioni, A., Savic, D. A., and Webb, B. W. (2007). "A multi-model approach to analysis of environmental phenomena." Environmental Modelling and Software, 22(5), 674-682.

Giustolisi, O., and Savic, D. A. (2006). "A symbolic data-driven technique based on evolutionary polynomial regression." Journal of Hydroinformatics, 8(3), 207222.

Goldberg, D. E. (1989). Genetic Algorithms in Search Optimization and Machine Learning, Addison - Wesley, Mass.

Hecht-Nielsen, R. (1990). Neurocomputing, Addison-Wesely Publishing Company, Reading, MA.

Kulhawy, F. H., and Mayne, P. W. (1990). "Manual on estimating soil properties for foundation design " Report EL-6800, Electric Power Research Institute, Palo Alto, CA.

Lau, D. S., and Simmons, J. V. (1986) "Interpretation of field tests on small-scale ground anchors." Specialty Geomechanics Symposium: Interpretation of Field Testing for Design Parameters, Adelaide, Barton (IEAust), 85-88.

Laucelli, D., Berardi, L., and Doglioni, A. (2009). "Evolutionary polynomial regression EPR Version 2.SA ", Department of Civil and Environmental Engineering, Technical Universoty of Bari, Bari, Italy.

Masters, T. (1993). Practical neural network recipes in $C++$, Academic Press, San Diego, California.

Meyerhof, G. G. (1965). "Shallow foundations." Journal of Soil Mechanics \& Foundation Engineering Division, 91(SM2), 21-31.

Reese, L. C., and O'Neill, M. W. (1988). "Drilled shafts: Construction procedures and design methods." FHWA-HI-88-042, U. S. Department of Transportation, Dallas, Texas.

Rezania, M., Faramarzi, A., and Javadi, A. (2011). "An evolutionary based approach for assessment of earthquake-induced soil liquefaction and lateral displacement." Engineering Applications of Artificial Intelligence, 24(1), 142-153.

Savic, D. A., Giustolisi, O., Berardi, L., Shepherd, W., Djordjevic, S., and Saul, A. (2006). "Modelling sewer failure by evolutionary computing." Proceedings of the Institution of Civil Engineers, Water Management 111-118.

Schmertmann, J. H. (1970). "Static cone to compute static settlement over sand." Journal of Soil Mechanics \& Foundation Engineering Division, 96(SM3), 10111043. 
Schmertmann, J. H. (1978). "Guidelines for cone penetration test, performance and design." FHWA-TS-78-209, U. S. Department of Transportation, Washington, D. C.

Schmertmann, J. H., Hartman, J. P., and Brown, P. B. (1978). "Improved strain influence factor diagrams." Journal of Geotechnical Engineering, 104(GT8), 1131-1135.

Schultze, E., and Sherif, G. (1973) "Prediction of settlements from evaluated settlement observations for sand." Proceedings of the 8th International Conference on Soil Mechanics \& Foundation Engineering, Moscow, 225-230.

Shahin, M. A. (2010). "Intelligent computing for modelling axial capacity of pile foundations." Canadian Geotechnical Journal, 47(2), 230-243.

Shahin, M. A. (2013). "Artificial intelligence in geotechnical engineering: applications, modeling aspects, and future directions." Metaheuristics in Water, Geotechnical and Transport Engineering, X. Yang, A. H. Gandomi, S. Talatahari, and A. H. Alavi, eds., Elsevier Inc., London, 169-204.

Shahin, M. A., and Jaksa, M. B. (2005). "Neural network prediction of pullout capacity of marquee ground anchors." Computers and Geotechnics, 32(3), 153-163.

Shahin, M. A., and Jaksa, M. B. (2006). "Pullout capacity of small ground anchors by direct cone penetration test methods and neural networks." Canadian Geotechnical Journal, 43(6), 626-637.

Shahin, M. A., Jaksa, M. B., and Maier, H. R. (2001). "Artificial neural network applications in geotechnical engineering." Australian Geomechanics, 36(1), 4962.

Shahin, M. A., Jaksa, M. B., and Maier, H. R. (2002a). "Artificial neural network-based settlement prediction formula for shallow foundations on granular soils." Australian Geomechanics, 37(4), 45-52.

Shahin, M. A., Jaksa, M. B., and Maier, H. R. (2009). "Recent advances and future challenges for artificial neural systems in geotechnical engineering applications." Journal of Advances in Artificial Neural Systems, 2009(Article ID: 308239), doi: 10.1155/2009/308239.

Shahin, M. A., Maier, H. R., and Jaksa, M. B. (2002b). "Predicting settlement of shallow foundations using neural networks." Journal of Geotechnical \& Geoenvironmental Engineering, 128(9), 785-793.

Shahin, M. A., Maier, H. R., and Jaksa, M. B. (2004). "Data division for developing neural networks applied to geotechnical engineering." Journal of Computing in Civil Engineering, 18(2), 105-114.

Su, W., and Fragaszy, R. J. (1988). "Uplift testing of model anchors." Journal of Geotechnical Engineering, 114(9), 961-983.

Terzaghi, K., and Peck, R. (1948). Soil mechanics in engineering practice, John Wiley $\&$ Sons, New York.

Zurada, J. M. (1992). Introduction to artificial neural systems, West Publishing Company, St. Paul. 
Table 1. Ranges of the data used in EPR model for settlement of shallow foundations

\begin{tabular}{lllll}
\hline Model variables & Minimum & Maximum & Mean & Standard deviation \\
\hline Footing width, $B(\mathrm{~m})$ & 0.8 & 60.0 & 8.7 & 10.2 \\
Footing net applied pressure, $q(\mathrm{kPa})$ & 18.3 & 697.0 & 187.0 & 126.0 \\
Average SPT blow count, $N$ & 4.0 & 60.0 & 24.0 & 13.0 \\
Footing length, $L(\mathrm{~m})$ & 0.8 & 101.0 & 16.6 & 18.7 \\
Footing embedment depth, $D_{f}(\mathrm{~m})$ & 0.0 & 10.7 & 2.3 & 1.9 \\
Measured settlement, $S(\mathrm{~mm})$ & 1.0 & 121.0 & 20.7 & 27.0 \\
\hline
\end{tabular}


Table 2. Analytical performance of EPR model for settlement of shallow foundations

\begin{tabular}{lll}
\hline Performance measure & Training set & Validation set \\
\hline$r$ & 0.940 & 0.923 \\
$R^{2}$ & 0.883 & 0.844 \\
$R M S E(\mathrm{~mm})$ & 9.25 & 9.83 \\
$M A E(\mathrm{~mm})$ & 5.70 & 6.99 \\
$\mu$ & 1.01 & 1.03 \\
\hline
\end{tabular}


Table 3. Comparison of EPR model and other methods in the validation set for settlement of shallow foundations

\begin{tabular}{|c|c|c|c|c|c|}
\hline \multirow{2}{*}{$\begin{array}{l}\text { Performance } \\
\text { measure }\end{array}$} & \multicolumn{5}{|l|}{ Method } \\
\hline & $\begin{array}{l}\text { EPR } \\
\text { (this study) }\end{array}$ & $\begin{array}{l}\text { ANNs } \\
\text { (Shahin et al. 2002) }\end{array}$ & $\begin{array}{l}\text { Meyerhof } \\
(1965)\end{array}$ & $\begin{array}{l}\text { Schultze and Sherif } \\
\text { (1973) }\end{array}$ & $\begin{array}{l}\text { Schmertmann et al. } \\
\text { (1978) }\end{array}$ \\
\hline$r$ & 0.923 & 0.905 & 0.440 & 0.729 & 0.838 \\
\hline$R^{2}$ & 0.844 & 0.803 & 0.014 & 0.185 & 0.153 \\
\hline RMSE (mm) & 9.83 & 11.04 & 24.71 & 22.48 & 22.91 \\
\hline$M A E(\mathrm{~mm})$ & 6.99 & 8.78 & 16.91 & 11.29 & 16.23 \\
\hline$\mu$ & 1.03 & 1.10 & 0.91 & 1.73 & 0.79 \\
\hline
\end{tabular}


Table 4. Ranges of the data used in EPR model for pullout capacity of ground anchors

\begin{tabular}{lllll}
\hline Model variables & Minimum & Maximum & Mean & Standard deviation \\
\hline Anchor equivalent diameter, $D(\mathrm{~mm})$ & 25.0 & 44.56 & 30.6 & 7.5 \\
Anchor embedment depth, $L(\mathrm{~mm})$ & 400.0 & 800.0 & 57.5 & 120.0 \\
Average cone tip resistance over anchor depth, $\bar{q}_{c}(\mathrm{MPa})$ & 0.95 & 3.55 & 1.97 & 0.58 \\
Average sleeve friction over anchor depth, $\bar{f}_{s}(\mathrm{kPa})$ & 12.22 & 179.71 & 60.6 & 43.2 \\
Ultimate pullout capacity, $Q_{u}(\mathrm{kN})$ & 0.29 & 3.80 & 1.77 & 0.75 \\
\hline
\end{tabular}


Table 5. Analytical performance of EPR model for pullout capacity of ground anchors

\begin{tabular}{lll}
\hline Performance measure & Training set & Validation set \\
\hline$r$ & 0.789 & 0.872 \\
$R^{2}$ & 0.619 & 0.753 \\
$R M S E(\mathrm{kN})$ & 0.46 & 0.43 \\
$M A E(\mathrm{kN})$ & 0.34 & 0.37 \\
$\mu$ & 1.02 & 0.99 \\
\hline
\end{tabular}


Table 6. Comparison of EPR model and other methods in the validation set for pullout capacity of ground anchors

\begin{tabular}{|c|c|c|c|c|c|}
\hline \multirow{2}{*}{$\begin{array}{l}\text { Performance } \\
\text { measure }\end{array}$} & \multicolumn{5}{|l|}{ Method } \\
\hline & $\begin{array}{l}\text { EPR } \\
\text { (this study) }\end{array}$ & $\begin{array}{l}\text { ANNs } \\
\text { (Shahin et al. 2005) }\end{array}$ & $\begin{array}{l}\text { LCPC } \\
(1982)\end{array}$ & $\begin{array}{l}\text { Das } \\
(1995)\end{array}$ & $\begin{array}{l}\text { Bowles } \\
\text { (1997) }\end{array}$ \\
\hline$r$ & 0.872 & 0.845 & 0.489 & 0.857 & 0.550 \\
\hline$R^{2}$ & 0.753 & 0.705 & -0.455 & -1.844 & -0.102 \\
\hline$R M S E(\mathrm{kN})$ & 0.43 & 0.47 & 1.03 & 1.45 & 0.90 \\
\hline$M A E(\mathrm{kN})$ & 0.37 & 0.37 & 0.88 & 0.98 & 0.61 \\
\hline$\mu$ & 0.99 & 0.95 & 1.84 & 0.72 & 1.86 \\
\hline
\end{tabular}


Table 7. Ranges of data used in EPR model for bearing capacity of pile foundations

\begin{tabular}{|c|c|c|c|c|}
\hline Model variables & Minimum & Maximum & Mean & Standard deviation \\
\hline \multicolumn{5}{|l|}{ Driven piles } \\
\hline Pile equivalent diameter, $D(\mathrm{~mm})$ & 250.0 & 900.0 & 448.8 & 130.9 \\
\hline Pile embedment depth, $L(\mathrm{~m})$ & 5.5 & 41.8 & 17.2 & 9.2 \\
\hline Weighted average cone point resistance over pile failure zone, $\bar{q}_{c-t i p}(\mathrm{MPa})$ & 0.0 & 20.0 & 5.2 & 4.8 \\
\hline Weighted average sleeve fiction over pile failure zone, $\bar{f}_{s-t i p}(\mathrm{kPa})$ & 0.0 & 300.0 & 96.6 & 95.7 \\
\hline Weighted average cone point resistance over pile embedment length, $\bar{q}_{c-s h a f t}(\mathrm{MPa})$ & 1.4 & 18.3 & 6.5 & 4.9 \\
\hline Weighted average sleeve fiction over pile embedment length, $\bar{f}_{s-s h a f t}(\mathrm{kPa})$ & 10.0 & 174.0 & 55.8 & 31.8 \\
\hline Ultimate capacity, $Q_{u}(\mathrm{kN})$ & 290.0 & 4460.0 & 1463.2 & 938.0 \\
\hline \multicolumn{5}{|l|}{ Drilled shafts } \\
\hline Pile stem diameter, $D(\mathrm{~mm})$ & 304.8 & 1798.3 & 617.0 & 372.0 \\
\hline Pile belled diameter, $B(\mathrm{~mm})$ & 304.8 & 2100.1 & 741.0 & 418.0 \\
\hline Pile embedment depth, L (m) & 4.5 & 27.4 & 10.0 & 4.7 \\
\hline Weighted average cone point resistance over pile failure zone, $\bar{q}_{c-t i p}(\mathrm{MPa})$ & 0.0 & 47.5 & 16.8 & 10.3 \\
\hline Weighted average sleeve fiction over pile failure zone, $\bar{f}_{s-t i p}(\mathrm{kPa})$ & 0.0 & 135.0 & 87.8 & 25.6 \\
\hline Weighted average cone point resistance over pile embedment length, $\bar{q}_{c-s h a f t}(\mathrm{MPa})$ & 1.1 & 28.8 & 8.2 & 5.2 \\
\hline Weighted average sleeve fiction over pile embedment length, $\bar{f}_{s-\text { shaft }}(\mathrm{kPa})$ & 19.0 & 132.0 & 73.7 & 17.0 \\
\hline Ultimate capacity, $Q u(\mathrm{kN})$ & 355.8 & 9652.2 & 2184.3 & 2161.5 \\
\hline
\end{tabular}


Table 8. Analytical performance of EPR model for bearing capacity of pile foundations

\begin{tabular}{lll}
\hline Performance measure & Training set & Validation set \\
\hline Driven piles & & \\
\hline$r$ & 0.910 & 0.848 \\
$R^{2}$ & 0.771 & 0.745 \\
$R M S E(\mathrm{kN})$ & 445 & 249 \\
$M A E(\mathrm{kN})$ & 314 & 185 \\
$\mu$ & 1.00 & 1.00 \\
\hline Drilled shafts & & \\
\hline$r$ & 0.965 & 0.990 \\
$R^{2}$ & 0.931 & 0.944 \\
$R M S E(k N)$ & 563 & 511 \\
$M A E(k N)$ & 409 & 347 \\
$\mu$ & 1.00 & 1.03 \\
\hline
\end{tabular}


Table 9. Comparison of EPR model and other methods in the validation set for bearing capacity of pile foundations

\begin{tabular}{|c|c|c|c|c|c|}
\hline \multirow{2}{*}{$\begin{array}{l}\text { Performance } \\
\text { measure }\end{array}$} & \multicolumn{5}{|c|}{ Methods for driven piles } \\
\hline & $\begin{array}{l}\text { EPR } \\
\text { (this study) }\end{array}$ & $\begin{array}{l}\text { ANNs } \\
\text { (Shahin 2010) }\end{array}$ & $\begin{array}{l}\text { European method } \\
(1979)\end{array}$ & $\begin{array}{l}\text { LCPC } \\
(1982)\end{array}$ & $\begin{array}{l}\text { Eslami and Fellenius } \\
\text { (1997) }\end{array}$ \\
\hline$r$ & 0.848 & 0.837 & 0.799 & 0.809 & 0.907 \\
\hline$R^{2}$ & 0.745 & 0.753 & 0.219 & 0.722 & 0.681 \\
\hline$R M S E(\mathrm{kN})$ & 249.0 & 244.0 & 435.0 & 260.0 & 278.0 \\
\hline$M A E(\mathrm{kN})$ & 185.0 & 203.0 & 382.0 & 219.0 & 186.0 \\
\hline$\mu$ & 1.00 & 0.97 & 1.36 & 1.11 & 0.94 \\
\hline \multirow{2}{*}{$\begin{array}{l}\text { Performance } \\
\text { measure }\end{array}$} & \multicolumn{5}{|c|}{ Methods for drilled shafts } \\
\hline & $\begin{array}{l}\text { EPR } \\
\text { (this study) }\end{array}$ & $\begin{array}{l}\text { ANNs } \\
\text { (Shahin 2010) }\end{array}$ & $\begin{array}{l}\text { Schmertmann } \\
\text { (1978) }\end{array}$ & $\begin{array}{l}\text { LCPC } \\
(1982)\end{array}$ & $\begin{array}{l}\text { Alsamman } \\
\text { (1995) }\end{array}$ \\
\hline$r$ & 0.990 & 0.970 & 0.901 & 0.951 & 0.984 \\
\hline$R^{2}$ & 0.944 & 0.939 & 0.578 & 0.901 & 0.939 \\
\hline$R M S E(\mathrm{kN})$ & 511.0 & 533.0 & 1404.0 & 681.0 & 534.0 \\
\hline$M A E(\mathrm{kN})$ & 347.0 & 374.0 & 702.0 & 426.0 & 312.0 \\
\hline$\mu$ & 1.03 & 1.02 & 1,33 & 0.97 & 1.03 \\
\hline
\end{tabular}




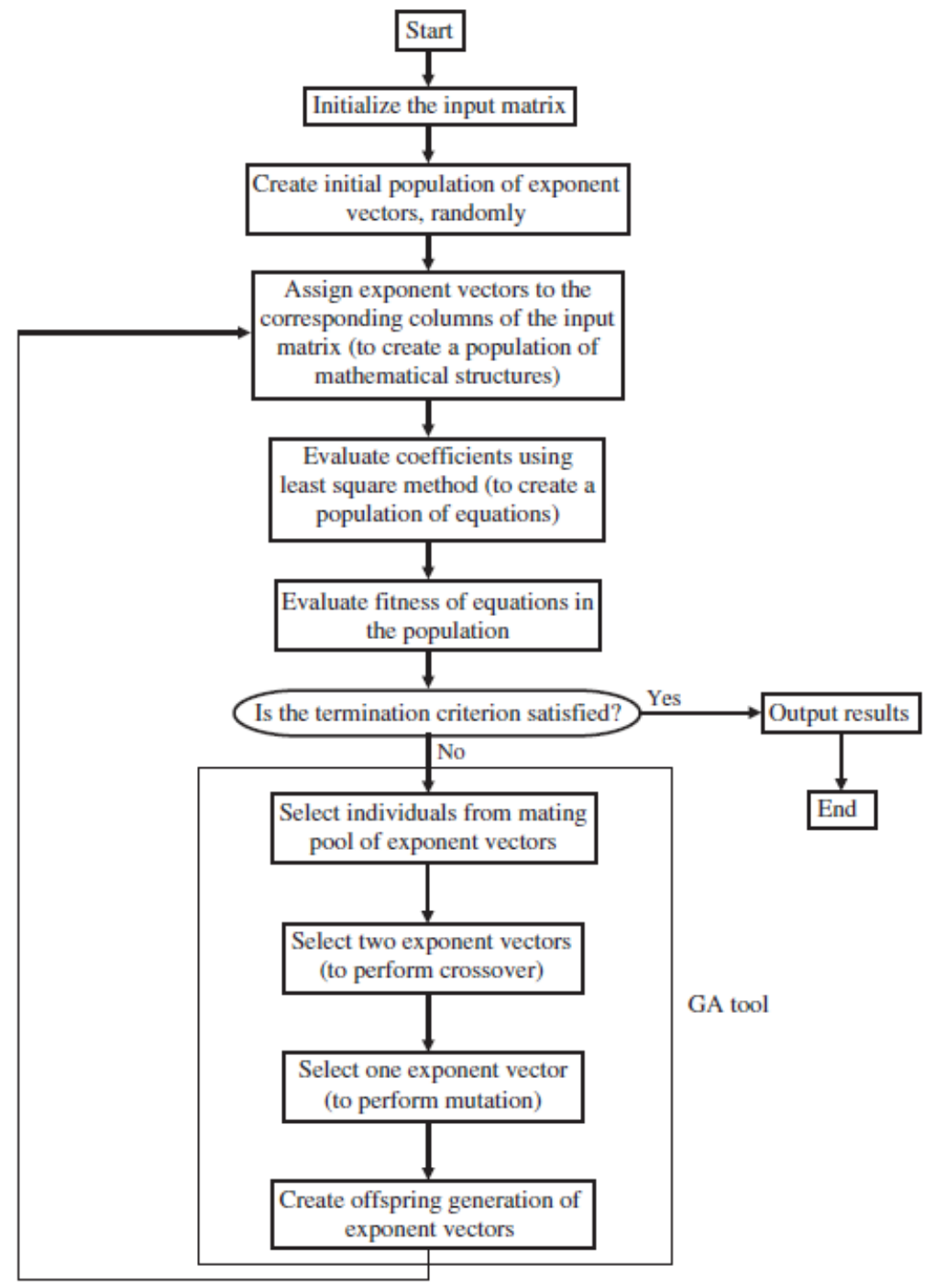

Figure 1. Typical flow diagram of EPR procedure (Rezania et al. 2011). 
(a) Training set $(r=0.940)$

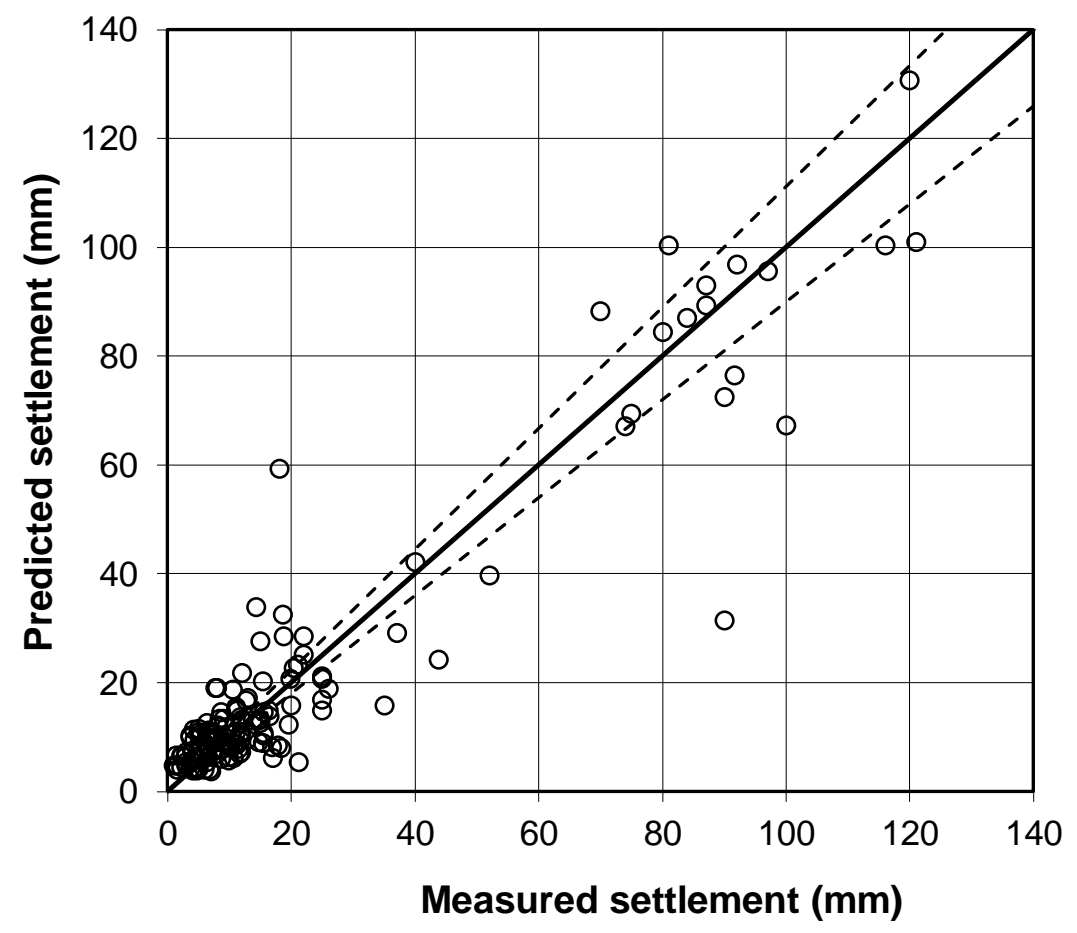

(b) Validation set $(r=0.923)$

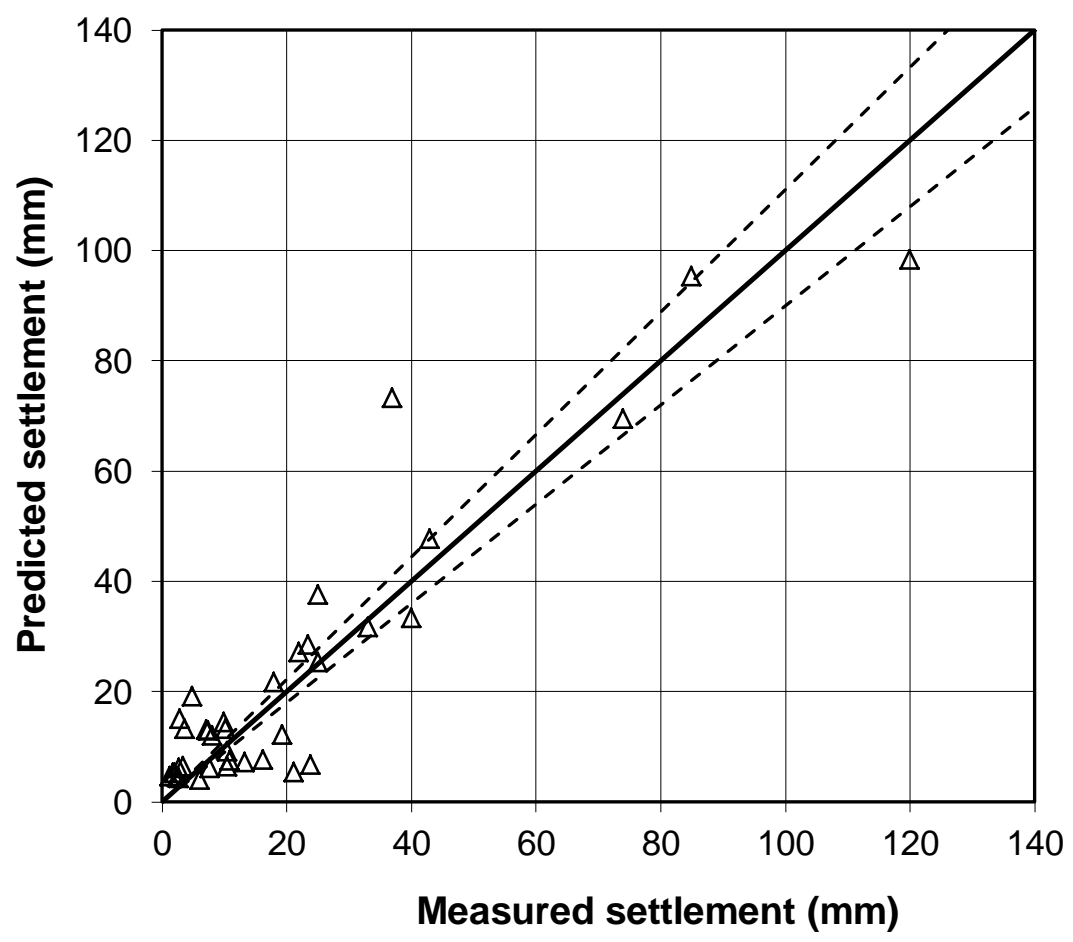

Figure 2. Performance of EPR model for settlement of shallow foundations: (a) training set; (b) validation set. 

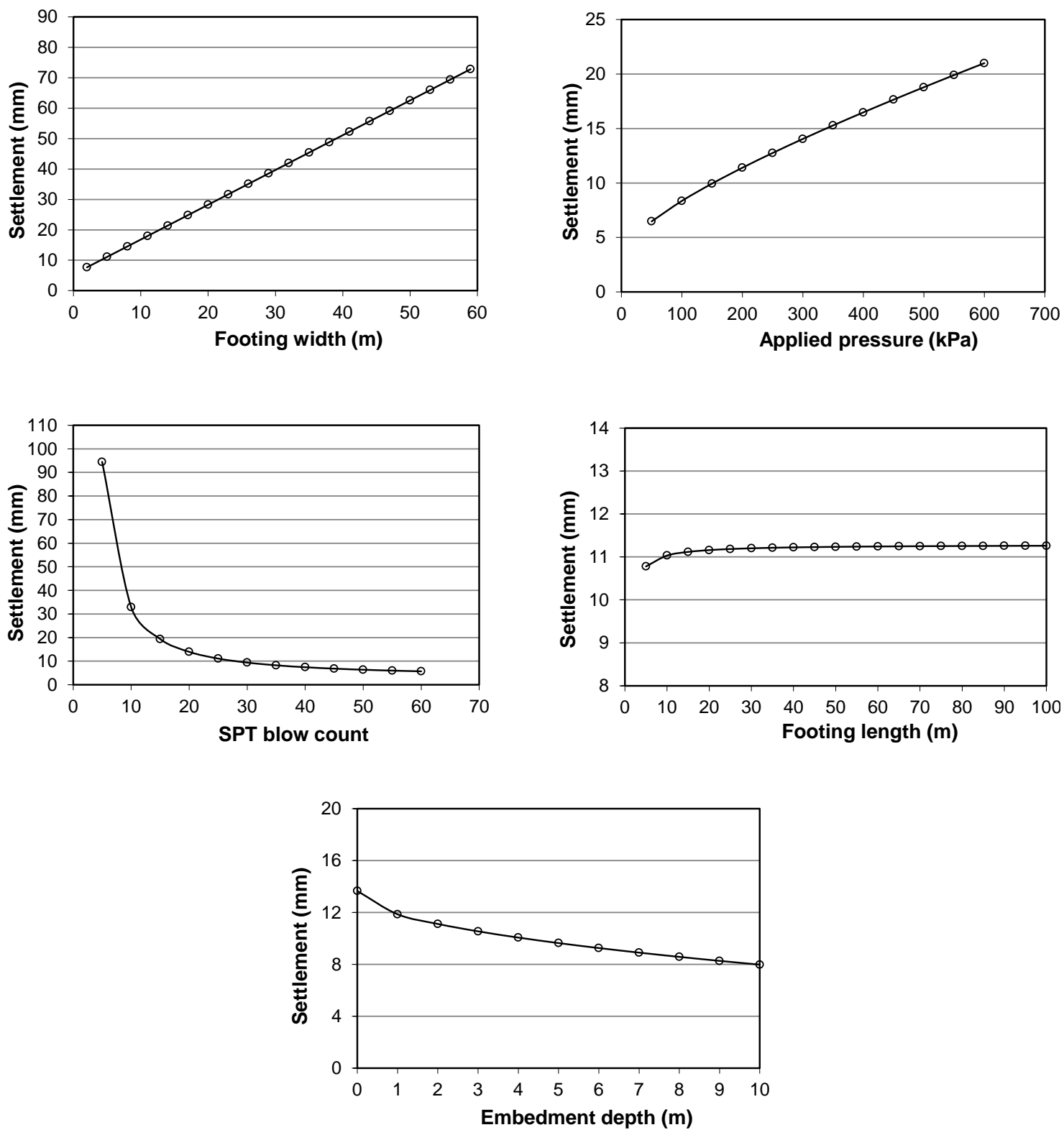

Figure 3. Sensitivity analysis of EPR model for settlement of shallow foundations. 
(a) Training set $(r=0.789)$

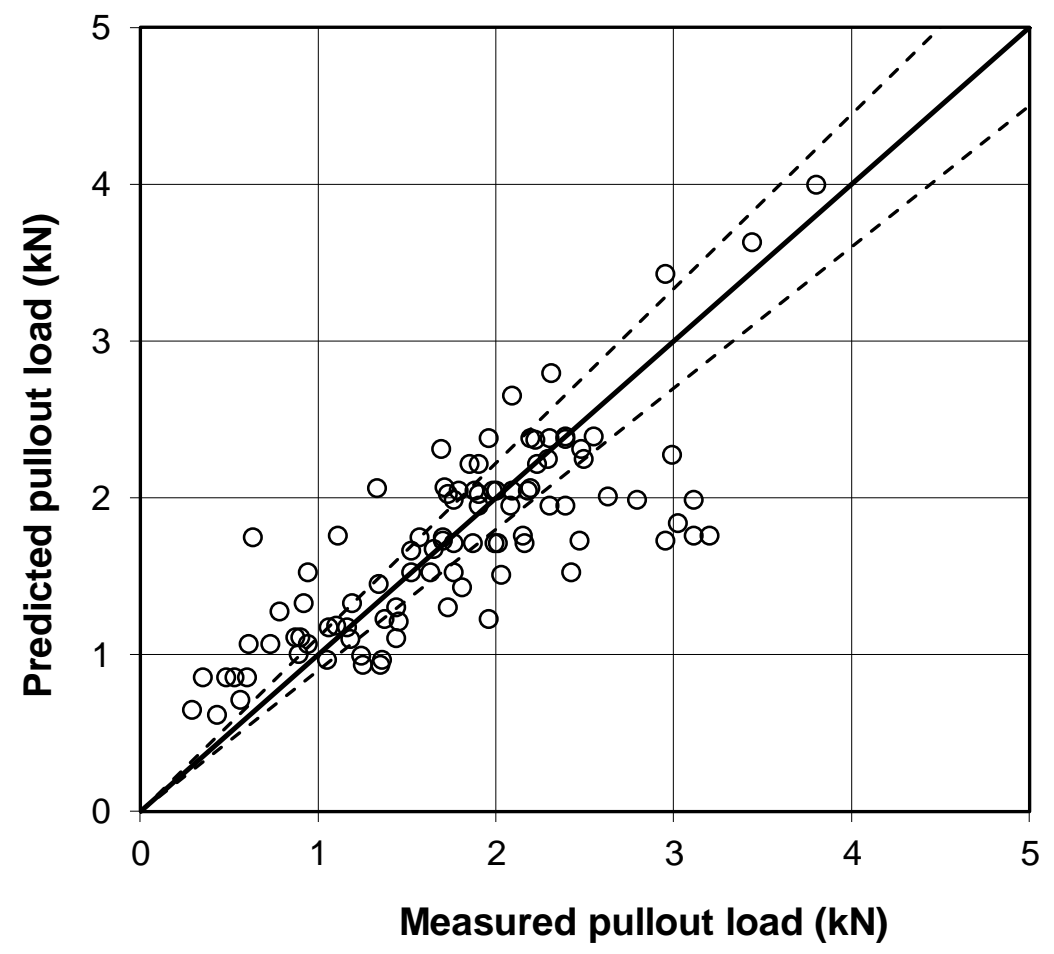

(b) Validation set $(r=0.872)$

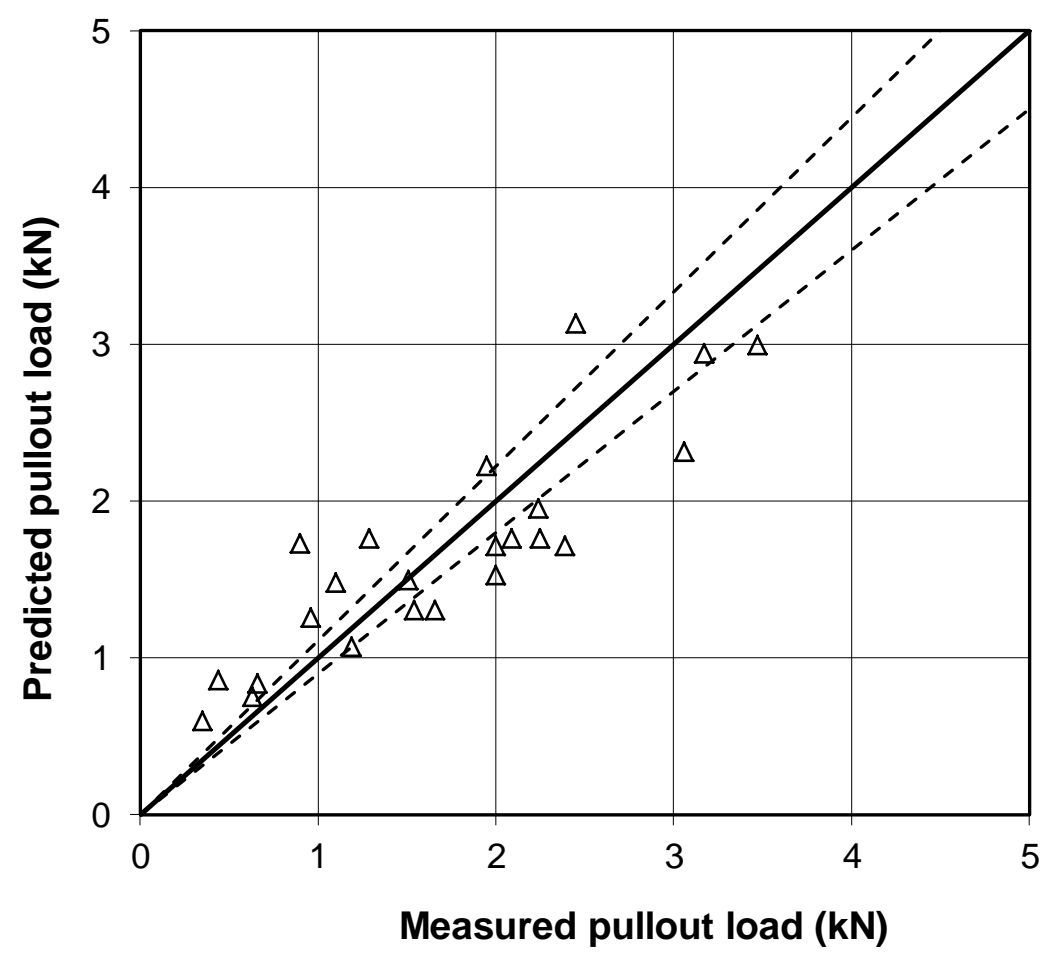

Figure 4. Performance of EPR model for pullout capacity of ground anchors: (a) training set; (b) validation set. 

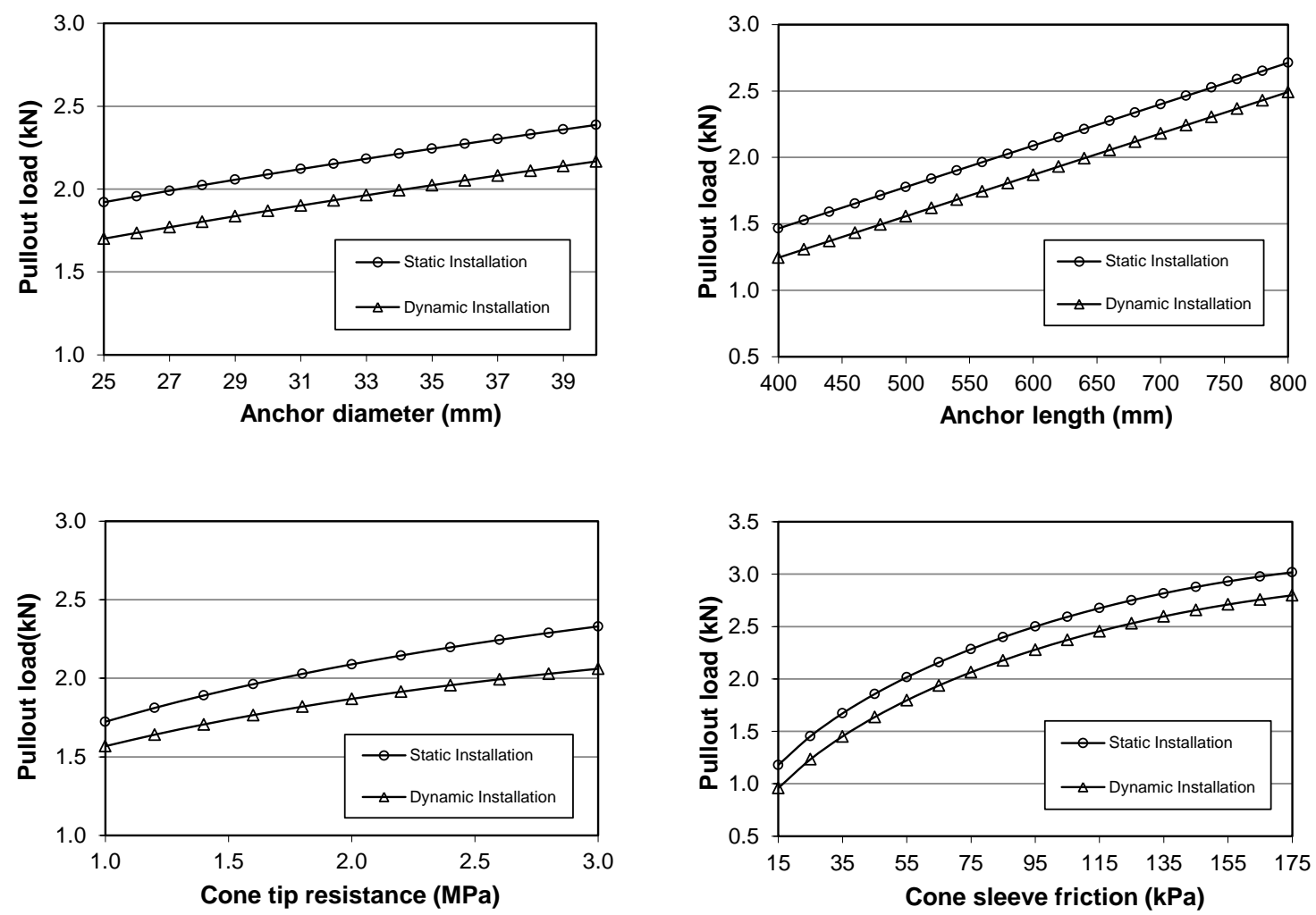

Figure 5. Sensitivity analysis of EPR model for pullout capacity of ground anchors. 
(a) Training set $(r=0.910)$

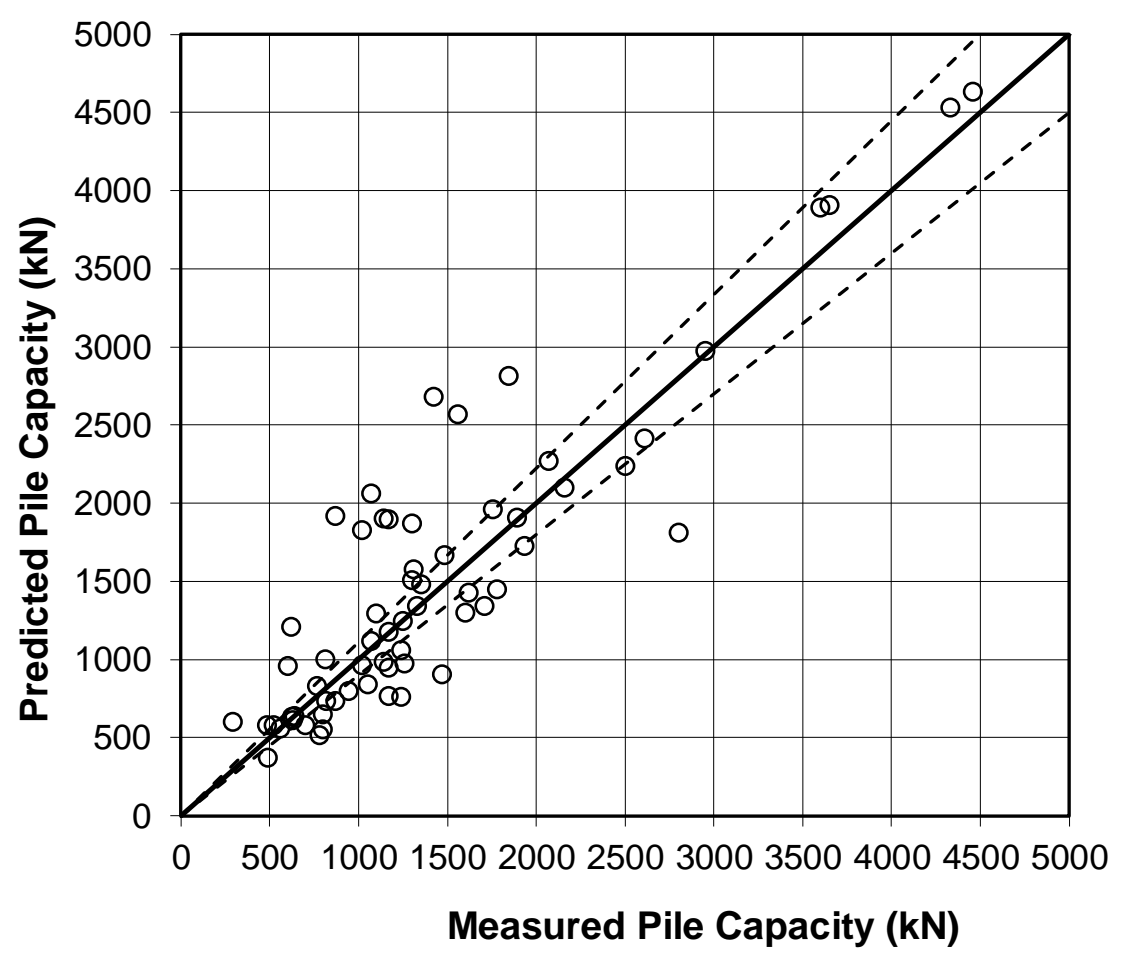

(b) Validation set $(r=0.848)$

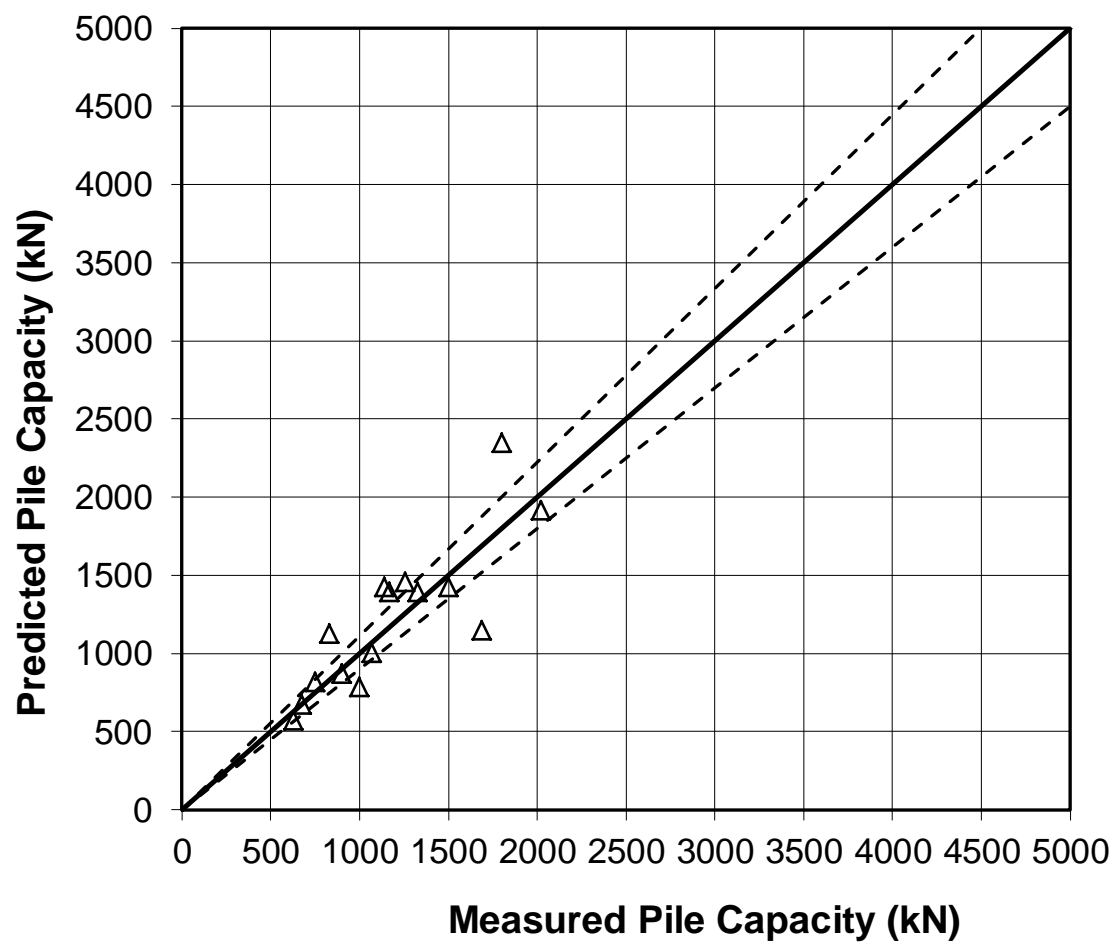

Figure 6. Performance of EPR models for bearing capacity of driven piles: (a) training set: (b) validation set. 

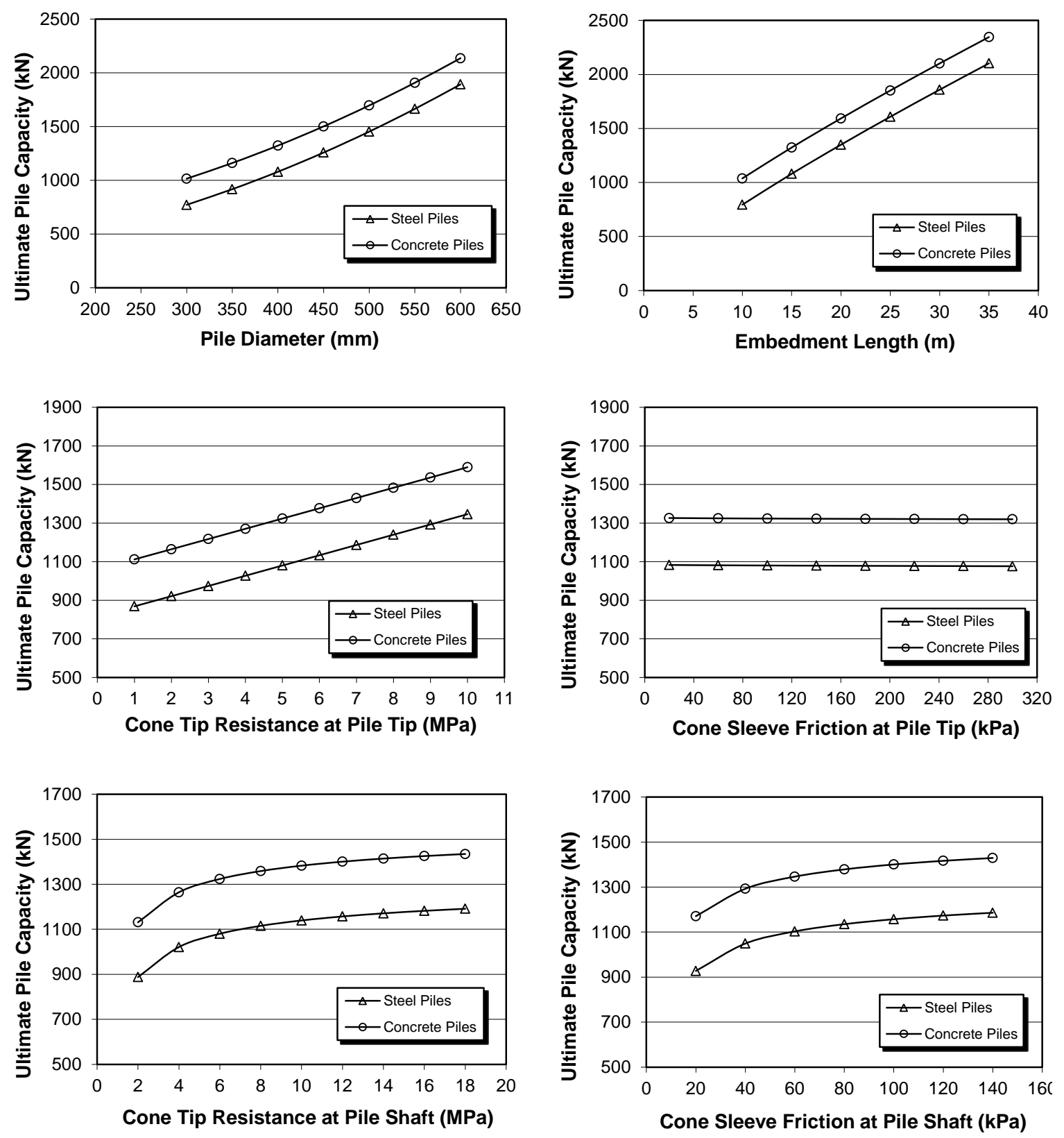

Figure 7. Sensitivity analysis of EPR models for bearing capacity of driven piles. 
(a) Training set $(r=0.965)$

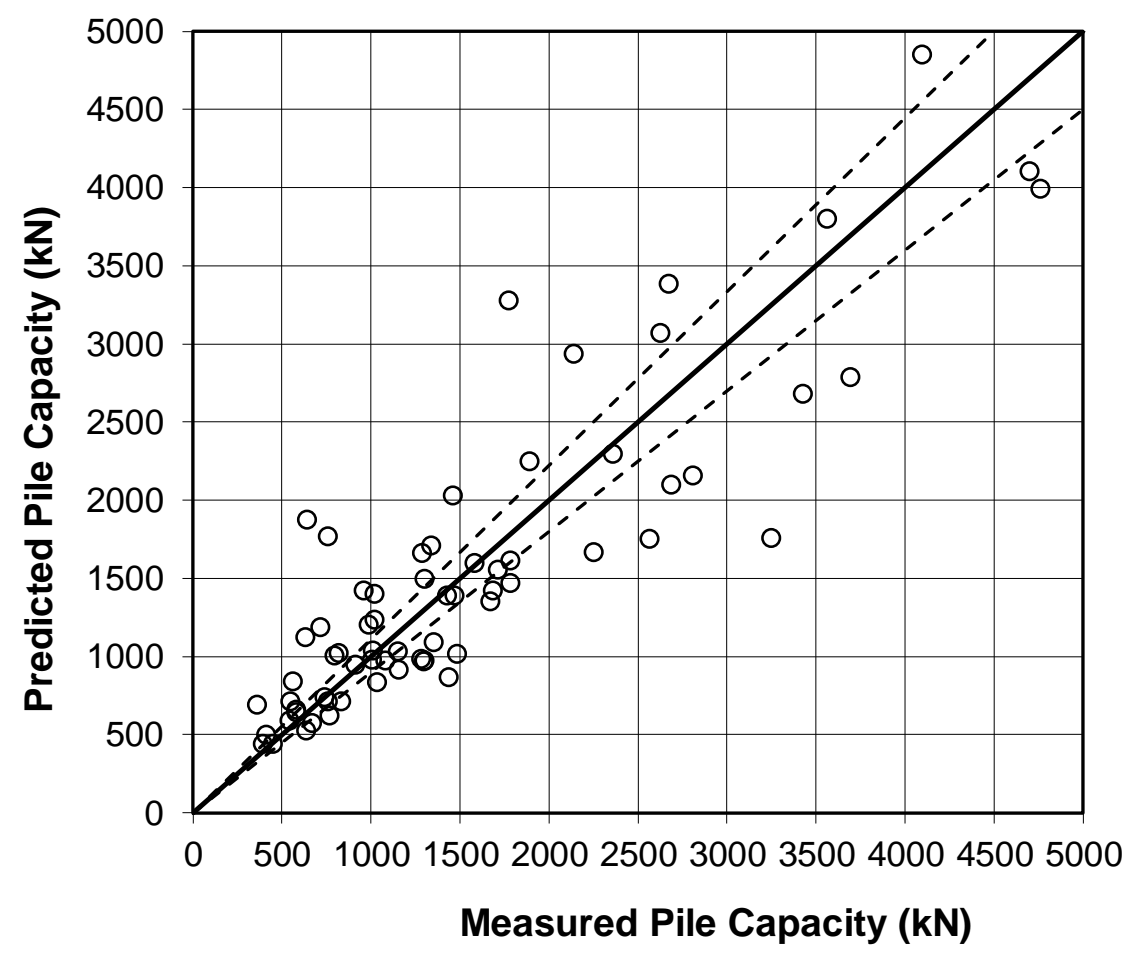

(b) Validation set $(r=0.990)$

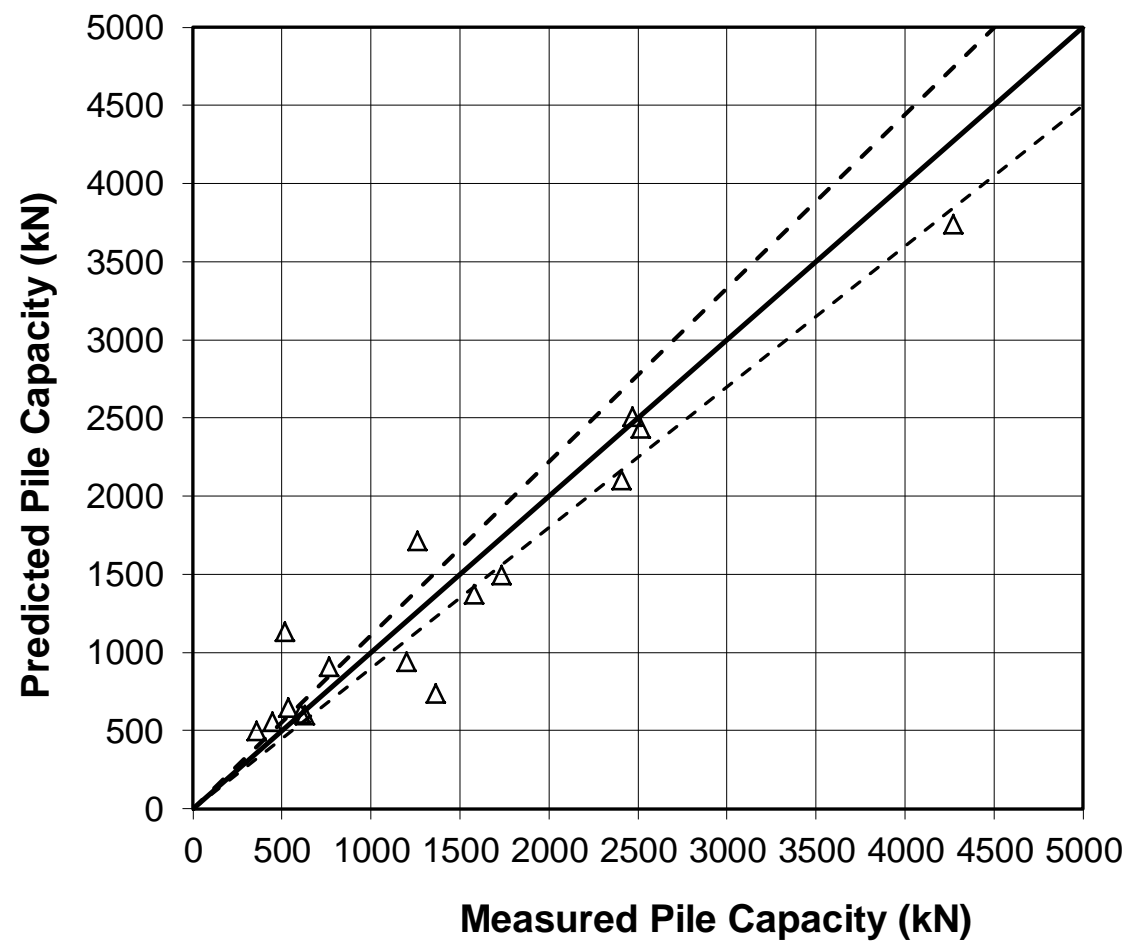

Figure 8. Performance of EPR models for bearing capacity of drilled shafts: (a) training set: (b) validation set. 


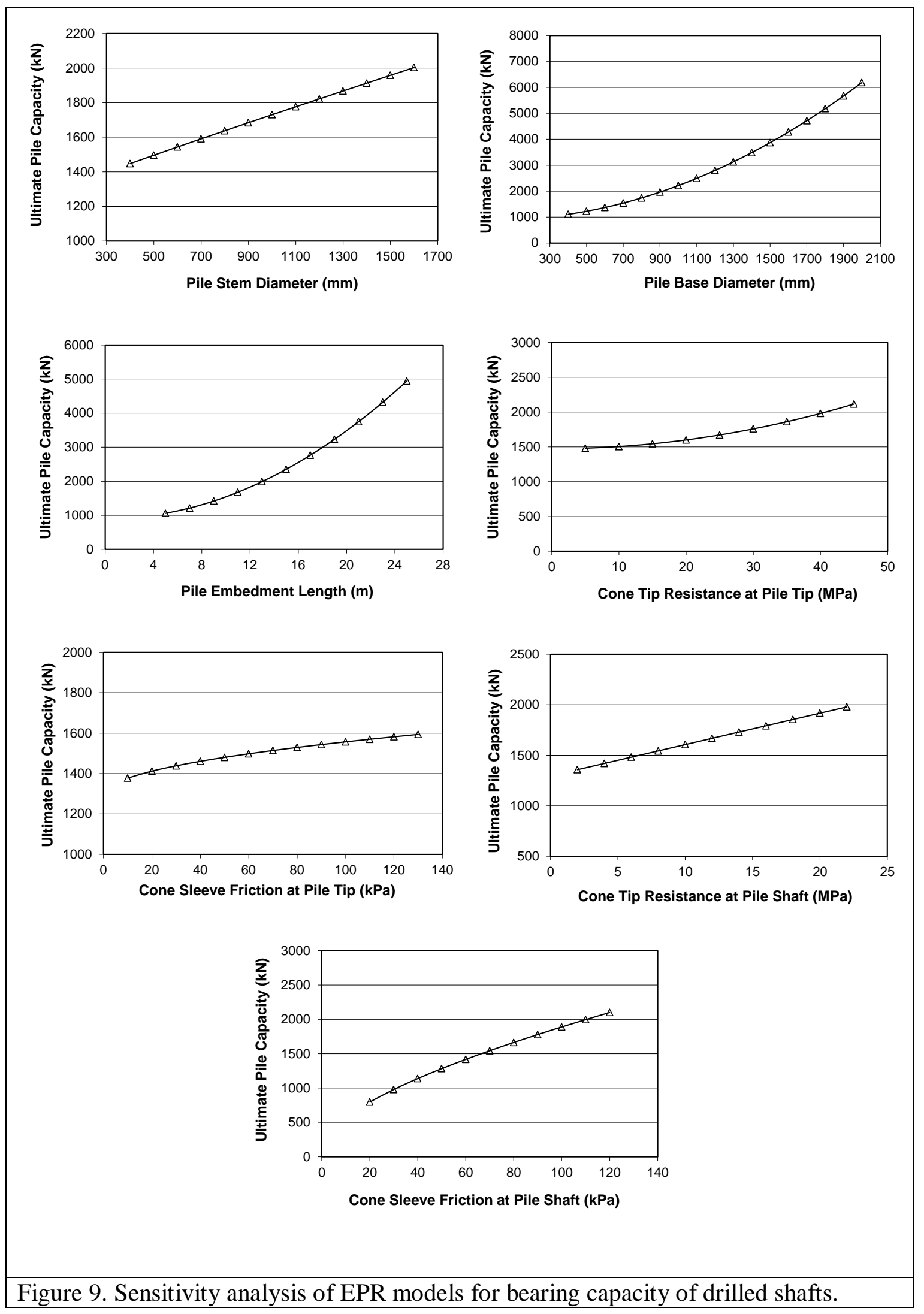

